NASA/TM—2013-216073

Effect of Two Advanced Noise Reduction Technologies on the Aerodynamic Performance of an Ultra High Bypass Ratio Fan

Christopher E. Hughes

Glenn Research Center, Cleveland, Ohio

John A. Gazzaniga

ASRC Aerospace Corporation 


\section{NASA STI Program . . . in Profile}

Since its founding, NASA has been dedicated to the advancement of aeronautics and space science. The NASA Scientific and Technical Information (STI) program plays a key part in helping NASA maintain this important role.

The NASA STI Program operates under the auspices of the Agency Chief Information Officer. It collects, organizes, provides for archiving, and disseminates NASA's STI. The NASA STI program provides access to the NASA Aeronautics and Space Database and its public interface, the NASA Technical Reports Server, thus providing one of the largest collections of aeronautical and space science STI in the world. Results are published in both non-NASA channels and by NASA in the NASA STI Report Series, which includes the following report types:

- TECHNICAL PUBLICATION. Reports of completed research or a major significant phase of research that present the results of NASA programs and include extensive data or theoretical analysis. Includes compilations of significant scientific and technical data and information deemed to be of continuing reference value. NASA counterpart of peer-reviewed formal professional papers but has less stringent limitations on manuscript length and extent of graphic presentations.

- TECHNICAL MEMORANDUM. Scientific and technical findings that are preliminary or of specialized interest, e.g., quick release reports, working papers, and bibliographies that contain minimal annotation. Does not contain extensive analysis.

- CONTRACTOR REPORT. Scientific and technical findings by NASA-sponsored contractors and grantees.
- CONFERENCE PUBLICATION. Collected papers from scientific and technical conferences, symposia, seminars, or other meetings sponsored or cosponsored by NASA.

- SPECIAL PUBLICATION. Scientific, technical, or historical information from NASA programs, projects, and missions, often concerned with subjects having substantial public interest.

- TECHNICAL TRANSLATION. Englishlanguage translations of foreign scientific and technical material pertinent to NASA's mission.

Specialized services also include creating custom thesauri, building customized databases, organizing and publishing research results.

For more information about the NASA STI program, see the following:

- Access the NASA STI program home page at http://www.sti.nasa.gov

- E-mail your question to help@sti.nasa.gov

- Fax your question to the NASA STI Information Desk at 443-757-5803

- Phone the NASA STI Information Desk at 443-757-5802

- Write to: STI Information Desk NASA Center for AeroSpace Information 7115 Standard Drive Hanover, MD 21076-1320 
NASA/TM—2013-216073

\section{Effect of Two Advanced Noise Reduction}

\section{Technologies on the Aerodynamic Performance of an Ultra High Bypass Ratio Fan}

Christopher E. Hughes

Glenn Research Center, Cleveland, Ohio

John A. Gazzaniga

ASRC Aerospace Corporation

National Aeronautics and

Space Administration

Glenn Research Center

Cleveland, Ohio 44135 


\section{Acknowledgments}

This work was performed under the support of the NASA Subsonic Fixed Wing Project in the Fundamental Aeronautics Program. The results obtained in the research described in this paper directly addresses Subsonic Fixed Wing Project goals to reduce Generation $\mathrm{N}+1$ aircraft noise, fuel burn and $\mathrm{NO}_{\mathrm{x}}$ environmental emissions. The authors would like to acknowledge the dedicated efforts of the Test Engineers in the Wind Tunnel and Propulsion Test Branch and the support crew at the 9- by 15-Foot Low-Speed Wind Tunnel at the NASA Glenn Research Center.

This work was sponsored by the Fundamental Aeronautics Program at the NASA Glenn Research Center.

Level of Review: This material has been technically reviewed by technical management.

Available from

NASA Center for Aerospace Information 7115 Standard Drive

Hanover, MD 21076-1320
National Technical Information Service 5301 Shawnee Road Alexandria, VA 22312

Available electronically at http://www.sti.nasa.gov 


\title{
Effect of Two Advanced Noise Reduction Technologies on the Aerodynamic Performance of an Ultra High Bypass Ratio Fan
}

\author{
Christopher E. Hughes \\ National Aeronautics and Space Administration \\ Glenn Research Center \\ Cleveland, Ohio 44135 \\ John A. Gazzaniga \\ ASRC Aerospace Corporation \\ Cleveland, Ohio 44135
}

\begin{abstract}
A wind tunnel experiment was conducted in the NASA Glenn Research Center anechoic 9- by 15-Foot LowSpeed Wind Tunnel to investigate two new advanced noise reduction technologies in support of the NASA Fundamental Aeronautics Program Subsonic Fixed Wing Project. The goal of the experiment was to demonstrate the noise reduction potential and effect on fan model performance of the two noise reduction technologies in a scale model Ultra High Bypass turbofan at simulated takeoff and approach aircraft flight speeds. The two novel noise reduction technologies are called Over-the-Rotor acoustic treatment and Soft Vanes. Both technologies were aimed at modifying the local noise source mechanisms of the fan tip vortex/fan case interaction and the rotor wake-stator interaction. For the Over-the-Rotor acoustic treatment, two noise reduction configurations were investigated. The results showed that the two noise reduction technologies, Over-the-Rotor and Soft Vanes, were able to reduce the noise level of the fan model, but the Over-the-Rotor configurations had a significant negative impact on the fan aerodynamic performance; the loss in fan aerodynamic efficiency was between $2.75 \%$ to $8.75 \%$, depending on configuration, compared to the conventional solid baseline fan case rubstrip also tested. Performance results with the Soft Vanes showed that there was no measurable change in the corrected fan thrust and a $1.8 \%$ loss in corrected stator vane thrust, which resulted in a total net thrust loss of approximately $0.5 \%$ compared with the baseline reference stator vane set.
\end{abstract}

\section{Introduction}

The NASA Fundamental Aeronautics Program Subsonic Fixed Wing Project (SFW) has set an aggressive noise reduction goal for the next generation $(\mathrm{N}+1)$ subsonic commercial aircraft of $32 \mathrm{~dB}$ cumulative below the current Stage 4 noise regulation. To meet this goal, a high fidelity wind tunnel experiment was conducted as part of the SFW Project to investigate and determine the noise reduction potential of two advanced noise reduction technologies for the Ultra High Bypass (UHB) engine cycle. These two technologies, Over-the-Rotor (OTR) metal foam acoustic liner treatment and acoustically treated Soft Vanes (SV), were tested using the NASA Glenn Research Center turbofan acoustic test bed propulsion simulator in the Glenn anechoic 9- x 15-Foot Low Speed Wind Tunnel (9'x15') at velocities simulating aircraft takeoff and landing speeds.

The objective of these technologies was to reduce the noise generated by the fan tip vortex/fan case interaction and the rotor wake/stator interaction. They were designed to modify the local unsteady pressure response to the flow and reduce the noise by redirecting and absorbing the acoustic energy. Acoustic results show that the OTR acoustic treatment configurations had a minimal impact on the fan model noise, while the SV configuration did produce significant noise reduction benefits. The acoustic results from this experiment are more fully described by Elliot and Woodward (Ref. 1). The effect of these technologies on the fan and stator aerodynamic performance was considered in the design process in an effort to minimize their impact. This paper presents the results obtained to measure their effect on the UHB model fan and stator aerodynamic performance. 


\section{Research Hardware}

The experiment used fan model hardware developed for the NASA/Pratt \& Whitney Advanced Ducted Propulsor (Ref. 2) and the NASA Fan Trailing Edge Blowing (Ref. 3) experiments, both being 18-bladed, 1.3 fan pressure ratio UHB fan models, and both previously tested at NASA Glenn. Whenever possible, as much legacy model hardware was used and as much of the original internal flowpath in the model was maintained. Fig. 1 shows photos of the fan model hardware installed on the Glenn drive rig in the 9x15 wind tunnel and a close-up of the fan disk. Fig. 2 is an illustration of the fan model showing the re-used hardware in silver and the new hardware pieces in color (except for the fan and spinner, which were existing hardware but colored for contrast).

The two noise reduction technologies investigated were designed to reduce the noise by manipulating the noise source mechanisms, the unsteady pressures generated when the local flow interacts with the physical model hardware. In Fig. 2 the locations of the two technologies in the fan model are shown. One of the noise reduction technologies, called Over-the-Rotor (OTR) treatment, was designed to address the noise generating mechanisms at the fan tip. The intent was to modify the interaction between the fan tip flow and the fan case. This was accomplished by incorporating a 1.5 inch thick layer of high porosity ( 80 to 100 pores per inch), low density ( $6 \%$ to $8 \%$, or $92 \%$ to $94 \%$ open area), metallic foam (described in Refs. 4 and 5) into the fan case above the fan tip. The metallic foam resembled a sponge material with a very large number of very small cavities. A portion of the sound pressure fluctuations would propagate into the foam instead of propagating into the free field, and would then be trapped or absorbed in the foam material.

Two different OTR design configurations were tested. The design rationale of the acoustically-treated rubstrips is described by Jones, et al. (Ref. 4). Sutliff, et al. (Ref. 5) has documented the noise reduction potential of this metal foam liner in experiments in the NASA Glenn Aeroacoustics Propulsion Laboratory (AAPL) using the Advanced Noise Control Fan, a very low pressure ratio device, as well as with a metal foam backed perforated rubstrip in a high speed turbofan application using a Williams International engine (Ref. 6). One design (FOAM) had the metal foam exposed on the flow surface, substituting for the normal rub material surface used at the fan tip. Pictures of the FOAM rubstrip are shown in Fig. 3. The other design (PERF) had a wearable, rigid plastic resin rub material shaped to duplicate the normal rubstrip flow surface backed by the metal foam. This configuration was intended to more realistically approach a conventional design fan case rubstrip flow surface. The plastic material was perforated with uniformly spaced holes 0.035 " in diameter, producing an open area that was $20 \%$ of the total flow surface area of the rub surface. The hole-diameter-to-length ratio was close to 1:3. The design intent was to allow the sound pressure fluctuations to pass unimpeded through the holes in the rub material and into the foam behind without significantly impacting the flow at the fan tip because of the small diameter of the holes in the rub material. Ideally, the flow would treat the rubstrip surface as a solid. Fig. 4 are pictures of the PERF rubstrip. In order to provide a baseline for comparison for the OTR designs, a conventional, solid hardwall (HW) rubstrip was also tested. A picture of the baseline rubstrip is shown in Fig. 5. A nominal gap of 0.030 " between the fan blade tip and the fan case rub surface was designed for all three rubstrip configurations tested, the two OTR and the baseline. For all three rubstrips, the tip gap was reduced to nominally 0.017 " at the maximum fan speed due to fan blade growth produced by the aerodynamic and centrifugal forces.

The second of the technologies, called Soft Vanes (SV), was designed to minimize the rotor-stator interaction noise generated as the fan wake impinges on the stator vanes. The design rationale behind the SV is discussed in Ref. 4. Again, the intent was to modify the noise generating mechanism by changing the unsteady pressure fluctuation response on the suction surface of the vanes. In this case, the stator vanes were hollow and divided into four separate internal chambers of varying length and internal volume. Each chamber was designed to act upon a certain frequency range of the interaction noise spectrum. Access to these internal chambers was provided by holes in the vane surface from $10 \%$ to $40 \%$ of the chord. This was determined analytically to be the location of maximum pressure response on the vanes where the fan wake impinges on the vane suction surface. The holes were then covered by a high impedance screen material to minimize the disturbances produced by airflow over the holes, and so minimize performance losses. The high impedance screen material provides a smooth aerodynamic surface, supporting steady pressures, but allows for the unsteady pressure perturbations to pass through in to the treatment Then, pressure waves in the designated specific frequencies propagated into the internal chambers and were dissipated, or canceled, preventing them from propagating into the farfield. There were a total of 25 vanes in the stator vane assembly. Fig. 6 is photos of the SV assembly and individual stator vane. Fig. 7 shows the acoustic treatment design and photos of internal vane structure. A set of solid metal stator vanes (HV) with the same aerodynamic design as the SV was also tested, in order to establish a baseline for comparison with the SV acoustic results. Fig. 8 is a picture of the HV stator assembly and an individual stator vane.

The fan aerodynamic performance was determined by measuring the pressure and temperature rise across the fan with four fixed, 10-element rakes located behind the fan between the fan and stators. Each rake element 
consisted of instrumentation to measure local total pressure and total temperature. A description of the instrumentation can be found in Ref. 2. Stator losses were determined by measuring the thrust produced using a sixcomponent static force balance, since there was no allowance made in the fan model for measuring pressure losses across the stators. Since the stators were an integral part of the nacelle system, including inlet, fan duct, cowl and bypass nozzle, the static balance measurements included force contributions from those elements as well. A twocomponent rotating force balance was used to measure the fan thrust and torque produced at the same time. By combining the two force balance measurements and correcting to standard day conditions, the total net thrust of the fan model system was determined. In this way, the impact of the SV on the complete fan model was measured. These measurements were made in conjunction with farfield acoustic testing, since the model was in the flight configuration with the complete nacelle installed and all pressure and temperature instrumentation was removed. A description of the force balance systems and their capabilities can be found in Ref. 7. Total weight flow into the model was determined from a previously defined curve fit of static pressure measurements in the model inlet with fan speed for the model hardware used.

\section{Test Plan}

The fan and stator aerodynamic performance was measured along a fixed operating line with a nozzle area sized to optimize fan performance at takeoff conditions for the baseline rubstrip configuration without treatments. The fan pressure and temperature rise and adiabatic efficiency were measured at several fan speeds along the operating line with each of the three OTR configurations installed - HW, PERF and FOAM - to determine their effect on the fan. Finally, the fan and stator thrust with the HV and SV configurations installed was measured using the rotating and static force balances at the same fan speed points while acoustic testing was conducted. The model is in the cleanest aerodynamically and is the closest simulation to the engine configuration during acoustic testing.

\section{Test Results}

In the succeeding sections, the effect of the two noise reduction technologies on the fan and stage aerodynamic performance is shown. The data displayed in Figures 9 through 24 have been tabularized and can be found in Appendix A.

\section{A. Comparison of Hardwall and Perforated OTR Rubstrips}

Figs. 9 to 11 illustrate the difference in aerodynamic performance between the hardwall (HW) baseline fan case rubstrip and the OTR perforated (PERF) rubstrip. The results show the fan performance drops with the PERF rubstrip installed compared with the hardwall. Fig. 9 shows that there is a loss in fan total pressure ratio with a corresponding loss in corrected total weight at all fan speeds. The loss in total pressure was from $0.1 \%$ to $0.5 \%$ with a drop in total weight flow from $0.6 \%$ to $1.3 \%$ as the fan speed increased from $55 \%$ to $100 \%$ of the fan design speed. The associated change in total temperature ratio is shown in Fig. 10. Here, the change in fan performance is shown as an increase in the total temperature, indicating a drop in performance produced as the fan tries to increase the energy in the flow. The resultant energy imparted to the flow is in the form of heat rather than an increase in pressure. The increase in temperature was from $0.1 \%$ to $0.2 \%$ compared to the HW rubstrip at the same fan speeds described above. In Fig. 11, the resultant drop in fan adiabatic performance is shown, illustrating the significant impact the PERF rubstrip has on the fan efficiency compared with the HW rubstrip. Loss in adiabatic efficiency ranges from $2.7 \%$ to $4.0 \%$ as the fan speed increases.

To better illustrate the effect of the PERF rubstrip on fan blade loading, Figs. 12 to 14 show the various parameter radial profiles produced from the fan exit performance rake data. Results are shown at three fan speeds; $62 \%, 86 \%$ and $100 \%$ of the fan design speed. These three speeds represent the aircraft acoustic rating point speeds of approach, cutback and takeoff for this engine cycle. They can also be used as reference speeds for illustrating detailed fan performance results since the speeds also span the fan operating line. In Fig. 12, the total pressure ratio profiles are shown for the PERF and HW rubstrips. As can be seen, the PERF rubstrip does have an impact on the local fan pressure loading. The fan loading is reduced along nearly the entire span of the blade, but is most significant in the outer half of the fan blade, especially near the fan tip, or the last roughly $20 \%$ of blade span. The difference in pressure rise ranges from $0.07 \%$ to $.43 \%$ as radius increases on the blade to sensor 8 , then jumps to a $1.40 \%$ drop at the last sensor near the fan tip at $100 \%$ fan speed. In Fig. 13, the total temperature ratio profiles are shown. Interestingly, the change in fan loading seems have a slightly positive effect on the total temperature rise since there is a slight decrease in total temperature inboard in the fan wake. At $100 \%$ fan speed, the total temperature decreases compared to the HW baseline by $0.03 \%$ to $0.08 \%$ from sensor locations 1 to 8 , then 
significantly increases by $1.48 \%$ at the fan tip as the PERF rubstrip disrupts the flow there. In Fig. 14, the distribution of adiabatic efficiency along the fan blade is shown. Again, the dramatic change in fan performance produced by the PERF rubstrip is illustrated at the fan tip with the large loss in efficiency. At $100 \%$ fan speed, peak adiabatic efficiency losses are $0.60 \%$ at $80 \%$ span, increasing to an $18.61 \%$ loss at $100 \%$ span. At other inboard radial locations on the fan blade, efficiency losses were much less, $+/-0.4 \%$ or less. This agrees with the slightly improved total temperature results inboard on the fan blade in Fig. 13, where the fan is better at doing work on the flow.

\section{B. Comparison of Hardwall and Exposed Metal Foam OTR Rubstrips}

In this section, the difference in fan performance with the hardwall (HW) baseline rubstrip and the exposed metal foam OTR acoustic treatment (FOAM) rubstrip will be discussed. Performance comparison plots are shown in Figs. 15 to 17. Fig. 15 shows the fan total pressure ratio and weight flow with fan speed along the fixed operating line for both rubstrip configurations. The loss in total pressure and weight flow follows the same trend as shown in Fig. 9, but the losses are significantly larger with the FOAM rubstrip; the losses in pressure and weight flow are almost double the losses with the PERF rubstrip in Fig. 9. Compared with the HW baseline rubstrip performance, the loss in total pressure is between $0.2 \%$ and $1.2 \%$ as the fan speed increases between $55 \%$ and $100 \%$, with a corresponding decrease in weight flow between $1.6 \%$ and $2.9 \%$ over the same speed range. In Fig. 16, the change in total temperature ratio shows the same trend as shown in Fig. 10, but also significantly larger. The increase in total temperature ranges between $0.1 \%$ and $0.4 \%$ as fan speed increases from $55 \%$ to $100 \%$, almost double the temperature increase seen with the PERF rubstrip in Fig. 10. Finally in Fig. 17, the loss in adiabatic efficiency is shown and is from $6.8 \%$ at $55 \%$ speed to as much as $9.3 \%$ at $100 \%$ speed. This figure clearly demonstrates that this OTR configuration is unacceptable due to the large losses in performance.

To better visualize the impact the FOAM rubstrip has on the fan blade loading, radial parameter profiles are shown in Figs. 18 to 20 comparing the FOAM and HW rubstrips. The huge impact on the blade flow can easily be seen in Figs. 18 and 19 by the dramatic pressure losses and temperature increases in the last roughly $40 \%$ of the fan blade span. The last four outboard radial measurement locations show losses in efficiency from $13.3 \%$ to $28.3 \%$ at $100 \%$ speed. Interestingly, a secondary flow phenomenon may be partially the cause of these large losses. Both pressure and temperature profiles show a large jump in losses and efficiency at the next to last radial measurement station on the rake, followed by a slight reversal in losses at the furthest outboard rake radial measurement location. It appears that the flow could be separating then reattaching, or that an external influence has caused unfavorable changes to the incoming flow incidence angle to the fan blade locally. Hot wire turbulence results presented in Ref. 1 indicate that the leading blade tip vortex looks to be significantly migrating toward the following blade. If this vortex flow is influencing the incoming flow of the following blade, the local fan blade performance could be significantly affected. In any case, the tip vortex flow phenomenon is occurring as a result of the open FOAM rubstrip as the fan flow is unimpeded by the rubstrip and reacts as if there is much more open gap at the fan tip.

\section{Comparison of Hard and Soft Stator Vanes}

In this section, the effect of the Soft Vanes (SV) on the fan and stator aerodynamic performance will be discussed. Thrust and torque produced by the fan and stators are used as the aerodynamic performance metric since there was no instrumentation located behind the stator vanes to make total pressure measurements. The SV performance is compared to a conventional, solid metal, baseline stator vane set (HV) designed to have similar aerodynamic of the SV. The corrected thrust and corrected torque of the fan, corrected thrust of the stator vanes, and the corrected total thrust of the fan and stators together are shown in Figs. 21 to 24. Since a measurement of the total weight flow was not available during this part of the test, the force numbers are plotted as a function of the percent corrected fan speed. Fig. 21 shows the corrected fan thrust produced as fan speed increases. Clearly, the differences in fan performance between the two different rubstrip configurations are very small, within the measurement accuracy of the force balance thrust which is $+/-5$ lbs. Fig. 22 shows the corrected fan torque produced as fan speed increases. This is a measure of the amount of work needed to drive the fan to produce thrust at the given fan speed. Again, the differences between the two rubstrips is small, however the SV do require slightly more power starting at fan speeds of $65 \%$ and above. The differences are small but measureable since accuracy of the force balance torque is $+/-3.5 \mathrm{ft}-\mathrm{lbs}$. The indication here is that there is a small increase in flow blockage with the SV that cause a minor backpressure on the fan that requires more power to achieve the same fan speed as the HV baseline. The blockage is most likely caused by the disturbed flow over the mesh screen covering the inlet hole interface to the SV chambers. If the screen is not perfectly aligned with the vane surface at the leading edge of the screen, the screen can trip the flow resulting in higher flow losses and turbulence. Fig. 23 bears this out, which 
shows the corrected stator thrust produced by the two stator vane assemblies. Here, the slightly reduced thrust produced by the SV compared to the HV can be seen at fan speeds beyond $85 \%$. The data shows the loss in thrust increasing as the fan speed increases. Still, the losses are small compared to the total stator thrust produced, shown in Fig. 24. The maximum loss is only $8 \mathrm{lbs}$. at $100 \%$ speed, which is $1.9 \%$ of the stator vane total thrust. Overall, the loss in corrected total thrust, the combination of fan and stator thrust, of the SV compared to the HV is no more than $7 \mathrm{lbs}$., or $0.5 \%$ of the corrected total thrust of $1,277 \mathrm{lbs}$. at $100 \%$ speed.

\section{Summary and Conclusion}

A test was conducted in the NASA Glenn 9'x15' Low Speed Wind Tunnel as part of the Fundamental Aeronautics Program Subsonic Fixed Wing Project to investigate the potential benefit of two advanced noise reduction technologies and their impact on the aerodynamic performance of an Ultra High Bypass turbofan model. The two technologies were called Over-the-Rotor (OTR) metal foam acoustic treatment and Soft Vanes (SV). Each technology was aimed at reducing the noise produced when flow from the fan interacts with hardware located in the flow path. In the case of OTR treatment, the acoustic pressure waves produced at the fan tip as part of the tip vortex flow were attenuated in the tortuous path in the very small cell, highly porous, metal foam located above the fan tip. Two OTR treatment designs were tested: one had the metal foam exposed to the flow and acted as the fan case rubstrip; and the other had the metal foam located behind a plastic resin material which had holes accounting for $20 \%$ of the total fan rubstrip area to allow the noise access to the foam behind the plastic rubstrip. In the case of the $\mathrm{SV}$, the pressure waves generated as the fan wake interacts with the downstream stator vanes were allowed to pass through a holes in the suction surface of the stator vanes and into tuned cavities within the hollow stator vane and dissipate in the cavities. In addition, the entry holes in the vanes were covered with a high impedance mesh prevented reflection of the pressure waves. This report addressed the effect these technologies had on the fan and stator aerodynamic performance.

The test results show that both of the OTR treatment designs had a significant impact on the fan performance compared with a hardwall, conventional rubstrip. The perforated OTR rubstrip has the least impact, but still reduced the total weight flow as much as $1.3 \%$ at $100 \%$ fan speed, with accompanying losses in total pressure of $0.5 \%$ and adiabatic efficiency by $4.0 \%$ compared with the solid hardwall baseline rubstrip. The exposed foam OTR rubstrip showed a very large impact on the performance, with losses slightly more than double those shown for the perforated OTR rubstrip. At $100 \%$ fan speed, the losses with the foam OTR rubstrip were $2.9 \%$ in weight flow, $1.2 \%$ in total pressure and $9.3 \%$ in adiabatic efficiency.

Fan and stator performance with the SV installed showed very small to negligible changes in fan and stator forces compared with the solid set of stator vanes used as a baseline reference. Forces measured from rotating and static force balances measured thrust and torque forces on the fan and stators. Combined fan and stator corrected total thrust results showed using the SV produced losses in total thrust of only $0.5 \%$ at $100 \%$ fan speed compared to the solid baseline stator vanes.

In conclusion, the performance test results presented in this paper show the effect of two advanced noise reduction technologies, Over-the-Rotor acoustic treatment and Soft Vanes, on the aerodynamic performance of the fan and stators. The results indicate that both Over-the-Rotor acoustic treatment designs produce large, unacceptable losses in fan aerodynamic performance compared to the performance using a conventional, solid hardwall rubstrip. Acoustic test results presented in Ref. 1 indicate the OTR rubstrips did have an impact on the fan model noise, but only in the middle of the range of fan speeds tested. Further research is required to reduce the fan losses to more acceptable levels ( $1 \%$ or less in fan adiabatic efficiency) and increase the noise reduction benefit at the lower and higher fan speeds. A modified rubstrip design that reduces the impact of the OTR acoustic treatment on the fan blade loading and fan tip flow needs to be investigated. Performance results with the Soft Vanes, however, show small losses in the thrust produced by the fan and stators compared with conventional, solid metal stator vanes. The performance losses are within the acceptable range (less than $1 \%$ of total system thrust). Based on the acoustic test results shown in Ref. 1, the SV also produce a significant benefit in reducing the fan model noise, thus making the SV noise reduction technology an attractive technology for further development into larger scale demonstration.

\section{References}

1. Elliot, D.E.; Woodward, R.P.; Podboy, G.P.; "Acoustic Performance of Unique Liner Locations for a High Bypass Model Turbofan at Simulated Flight Conditions," AIAA-2009-3140.

2. Jeracki, R.J.; "Comprehensive Report of Fan Performance from Duct Rake Instrumentation on 1.294 Pressure Ratio, 806 ft/sec Tip Speed Turbofan Simulator Models,” NASA/TM-2006-213863, 2006. 
3. Fite, E.B.; Woodward, R.P.; Podboy, G.G.; "Effect of Trailing Edge Flow Injection on Fan Noise and Aerodynamic Performance," AIAA 2006-2844.

4. Jones, M.G.; Parrott, T.L.; Sutliff, D.L.; Hughes, C.E.; "Assessment of Soft Vane and Metal Foam Engine Noise Reduction Concepts," AIAA-2009-3142.

5. Sutliff, D.L.; Jones, M.G.; "Foam-Metal Liner Attenuation of Low-Speed Fan Noise," AIAA-2008-2897.

6. Sutliff, D.L.; Elliot, D.E.; Jones, M.G.; Hartley, T.C.; "Attenuation of FJ44 Turbofan Engine Noise with a Foam-Metal Liner Installed Over-The-Rotor," AIAA-2009-3141.

7. Jeracki, R.J.; "Model Engine Performance Measurement From Force Balance Instrumentation," NASA/TM1998-208486. 

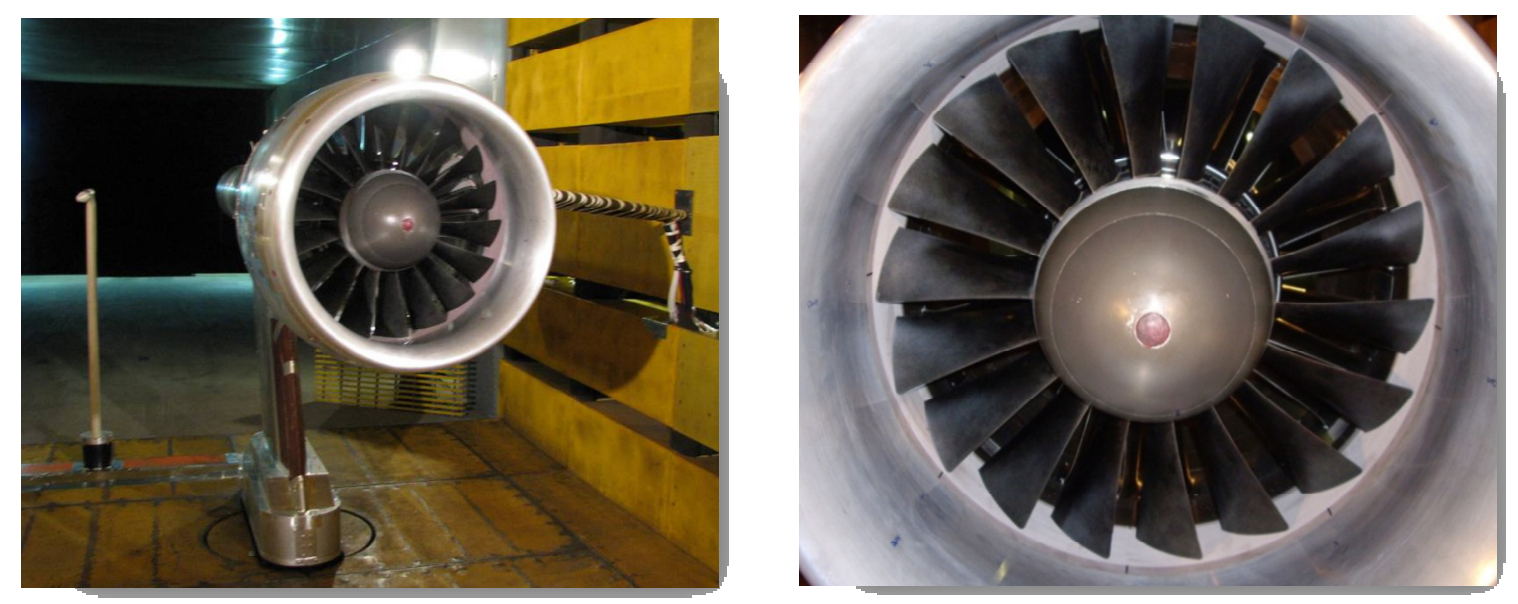

Figure 1. Ultra High Bypass fan model hardware installed in the NASA Glenn 9'x15' LSWT.

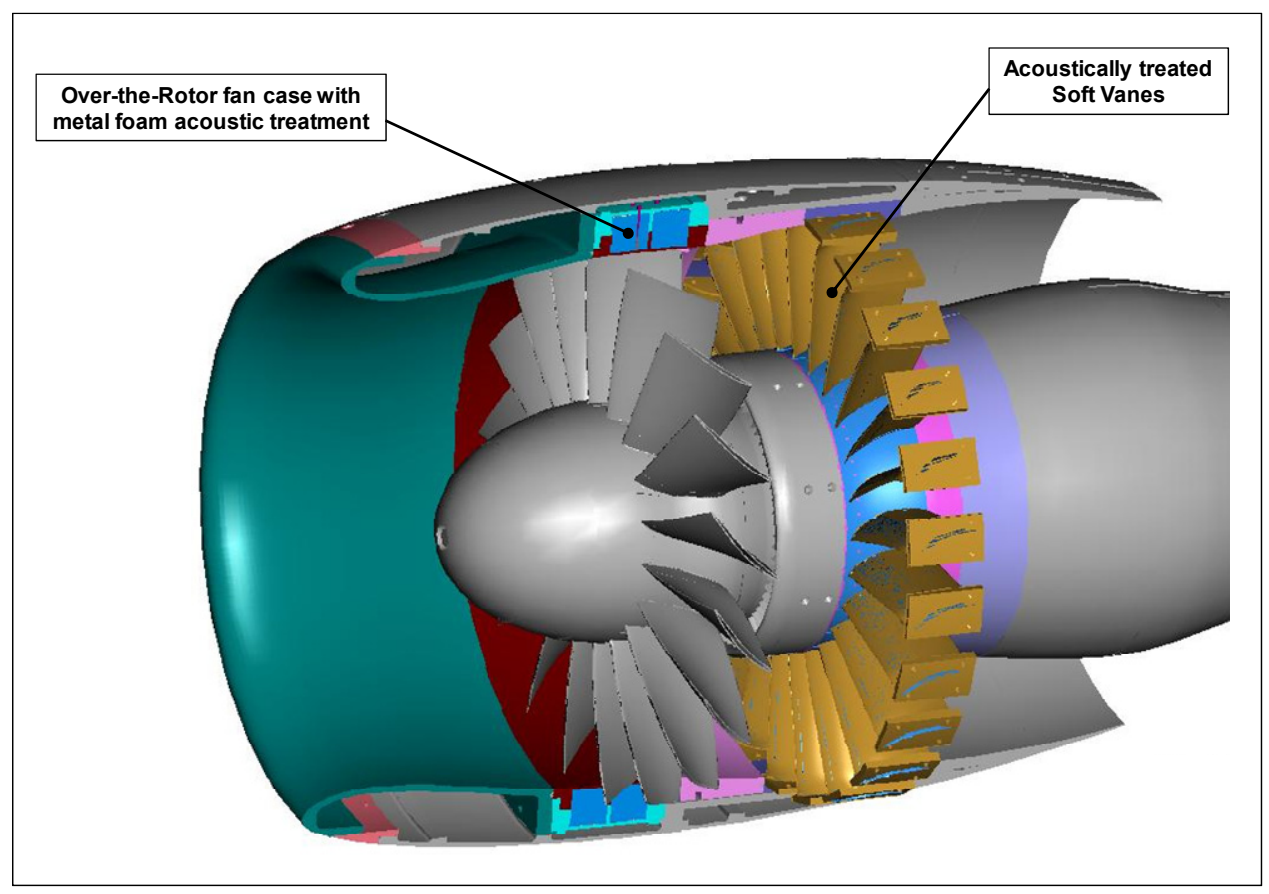

Figure 2. Illustration of the UHB fan model indicating existing hardware in silver and new hardware in color, and locations of noise reduction technologies. 


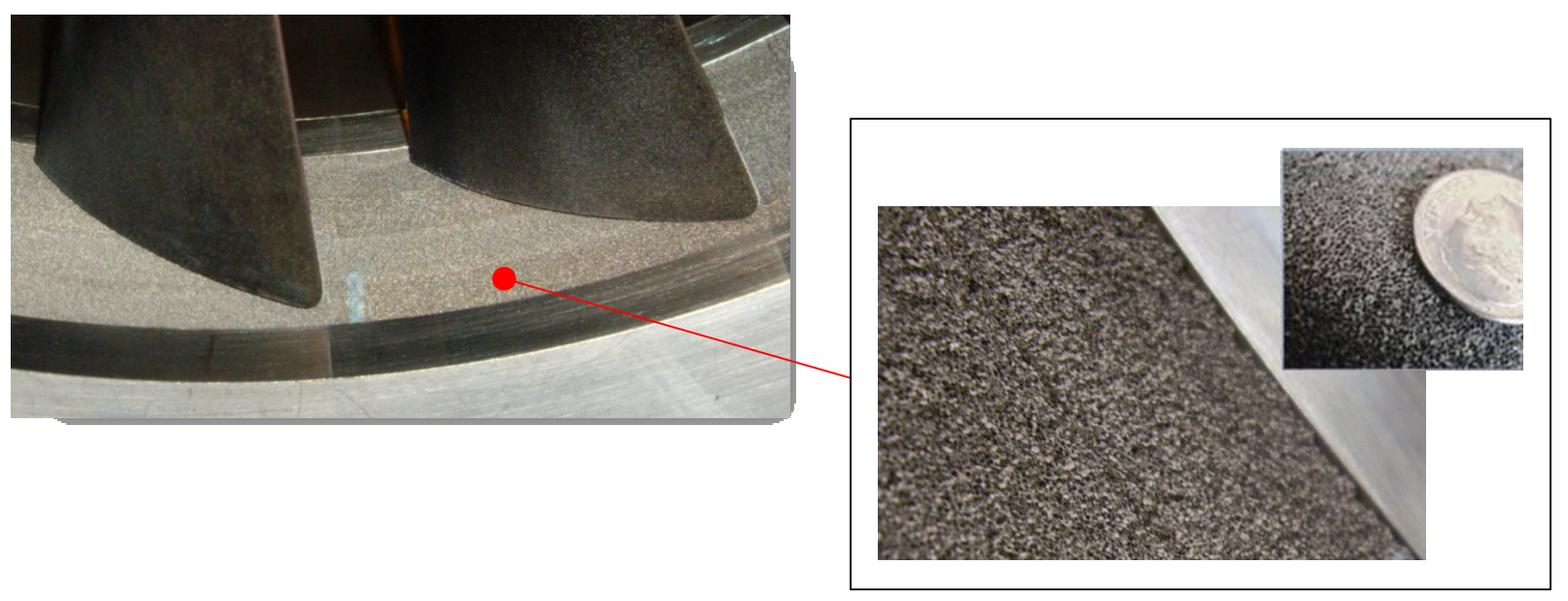

Figure 3. Fan case with exposed metal foam (FOAM) rubstrip.

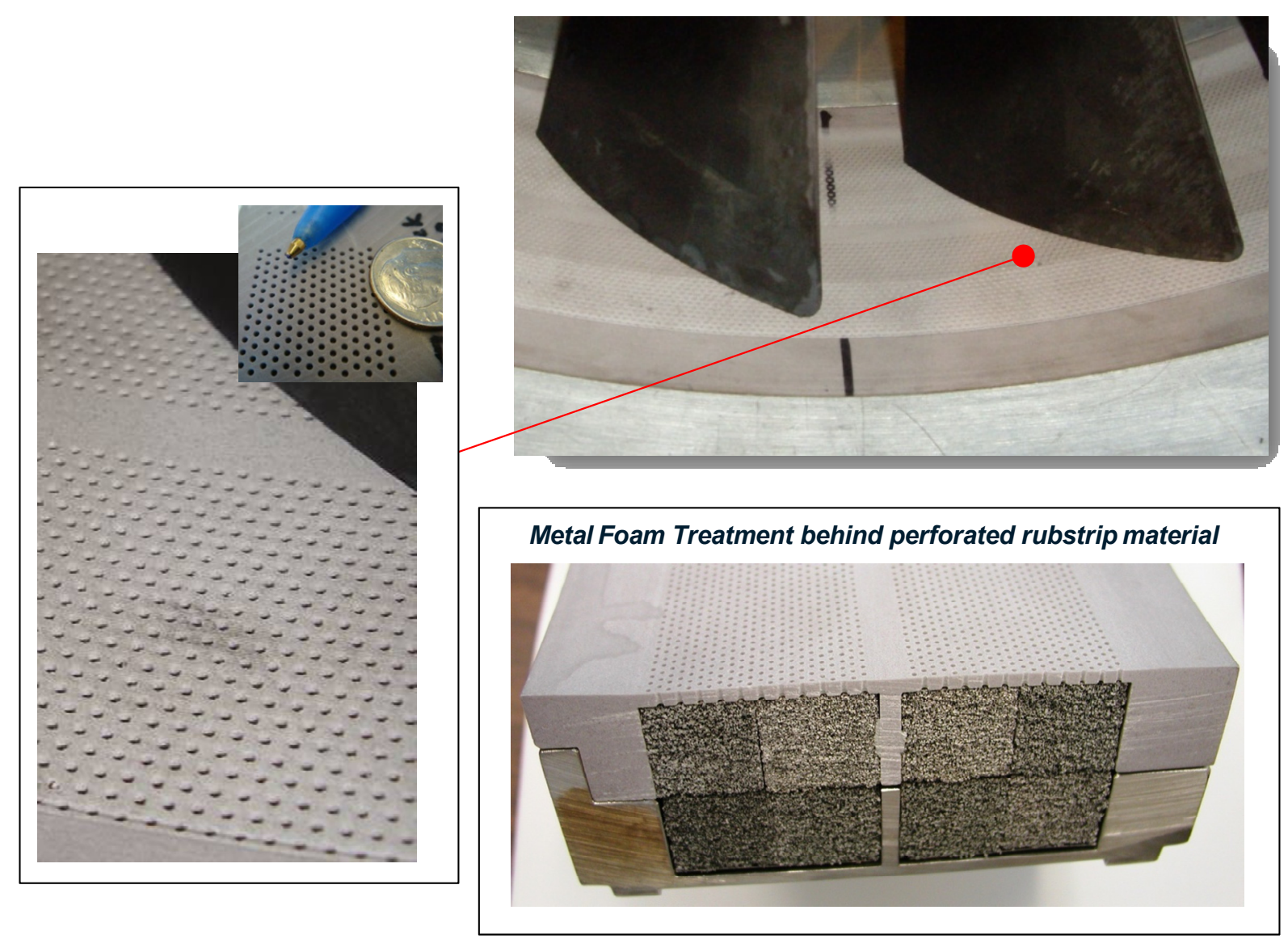

Figure 4. Fan case with perforated (PERF) rubstrip. 


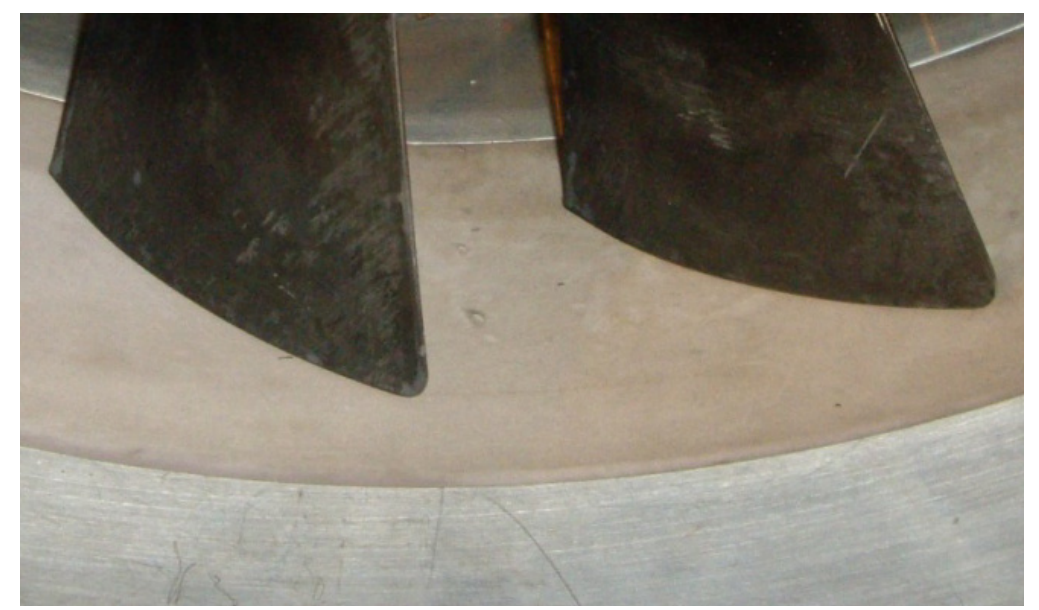

Figure 5. Baseline hardwall (HW) fan case rubstrip.
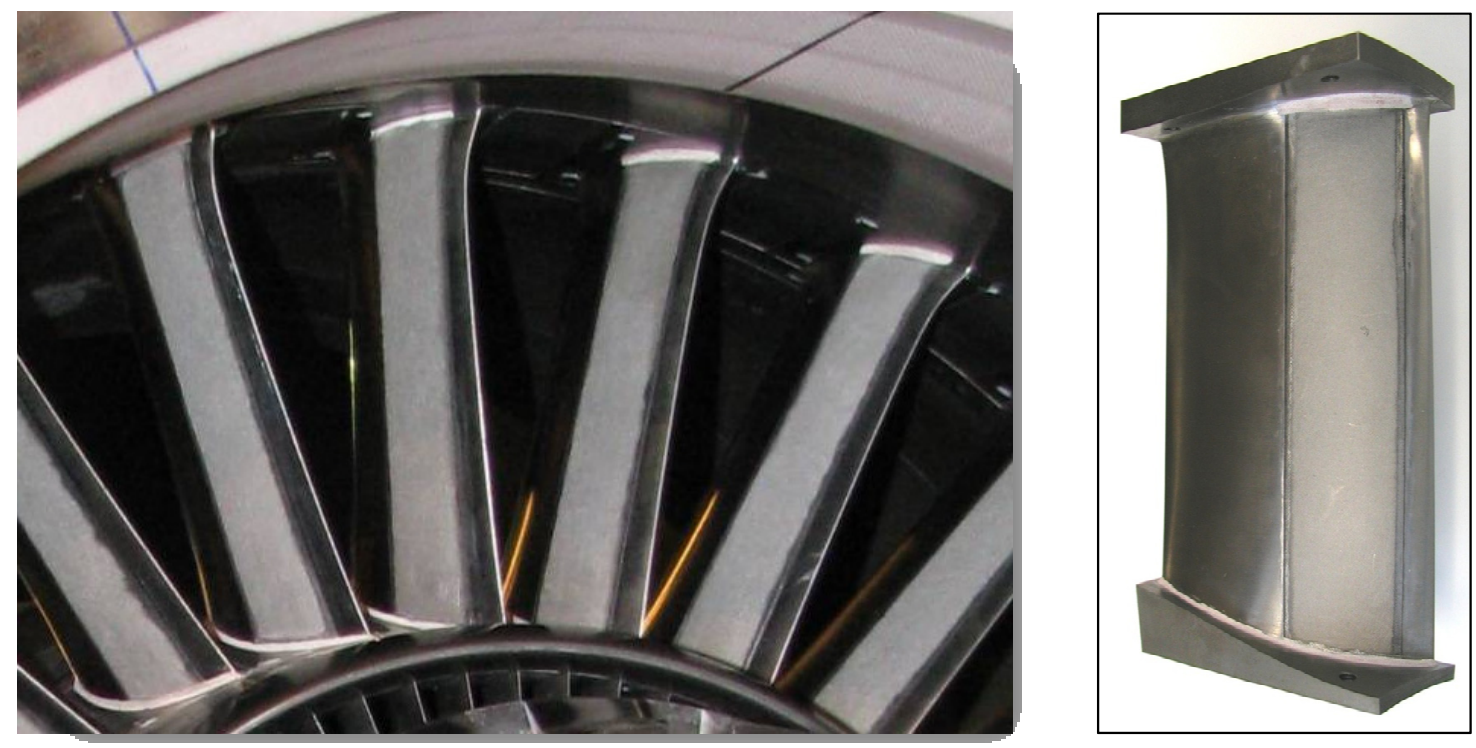

Figure 6. Acoustically treated Soft Vanes (SV), forward looking aft.
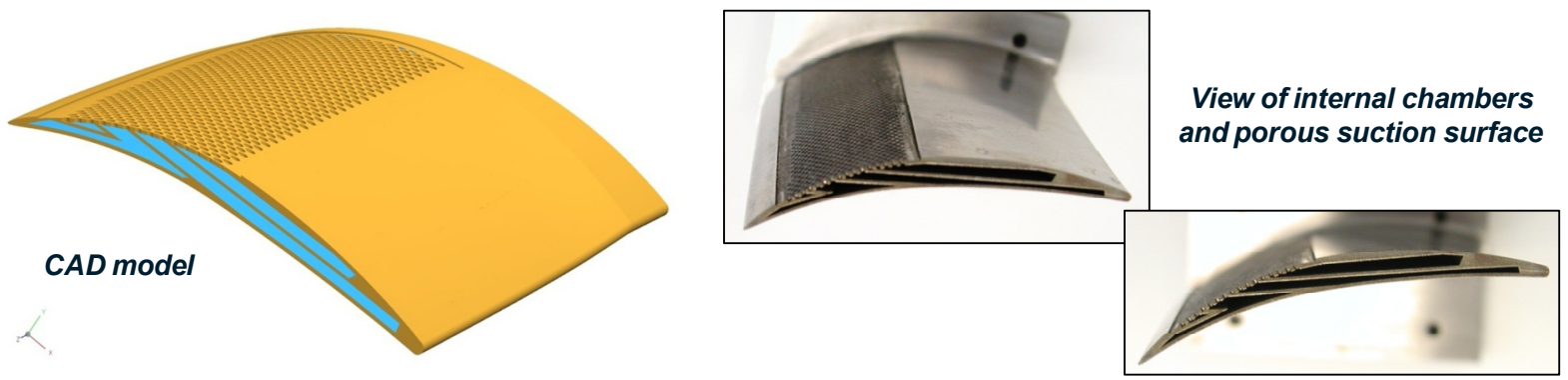

Figure 7. Details of Soft Vane acoustic treatment design; leading edge of vane is on the left. 

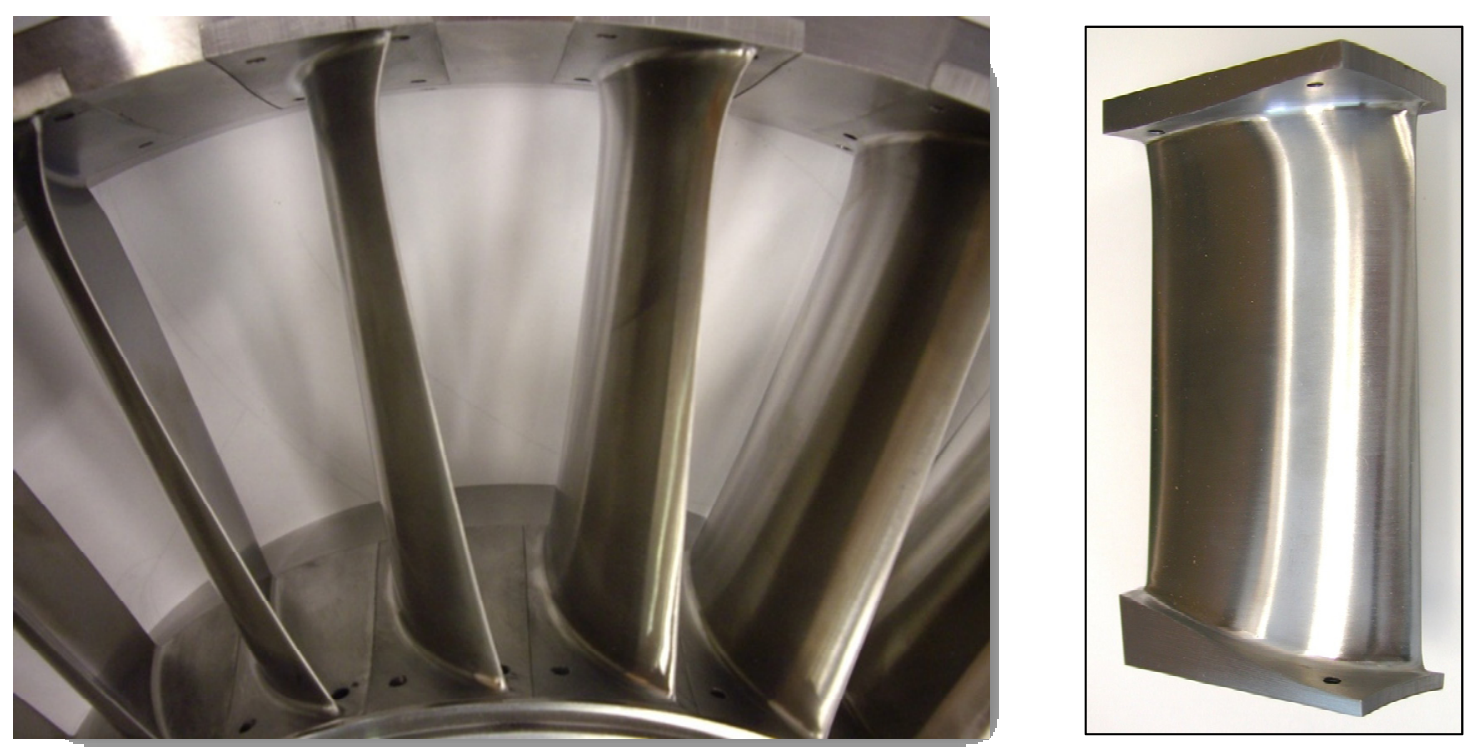

Figure 8. Solid Hard Vane (HV) baseline stator vanes.

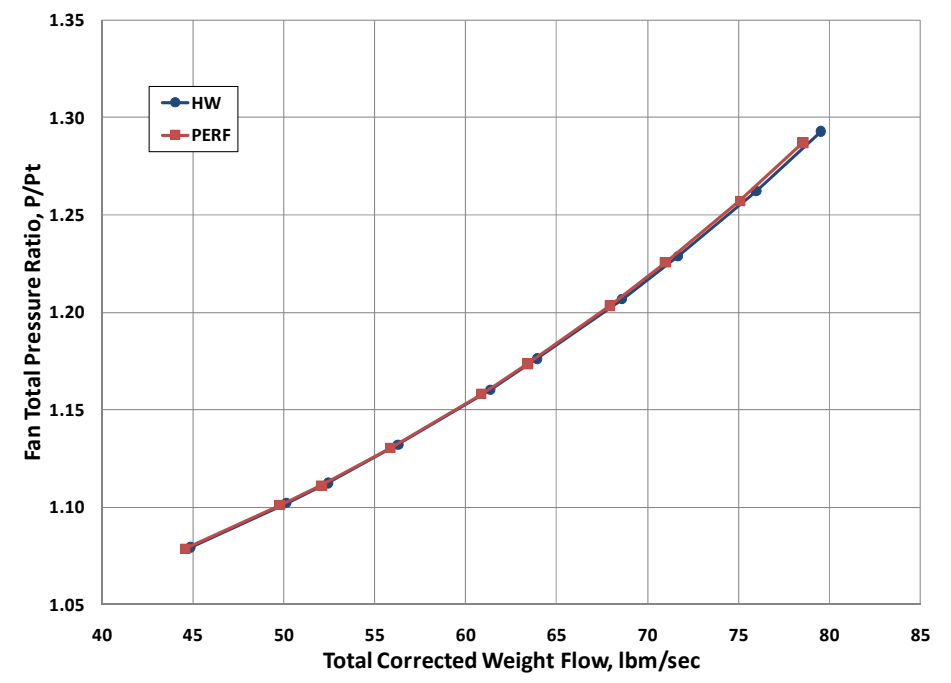

Figure 9. Comparison of fan pressure rise between HW and PERF rubstrips. 


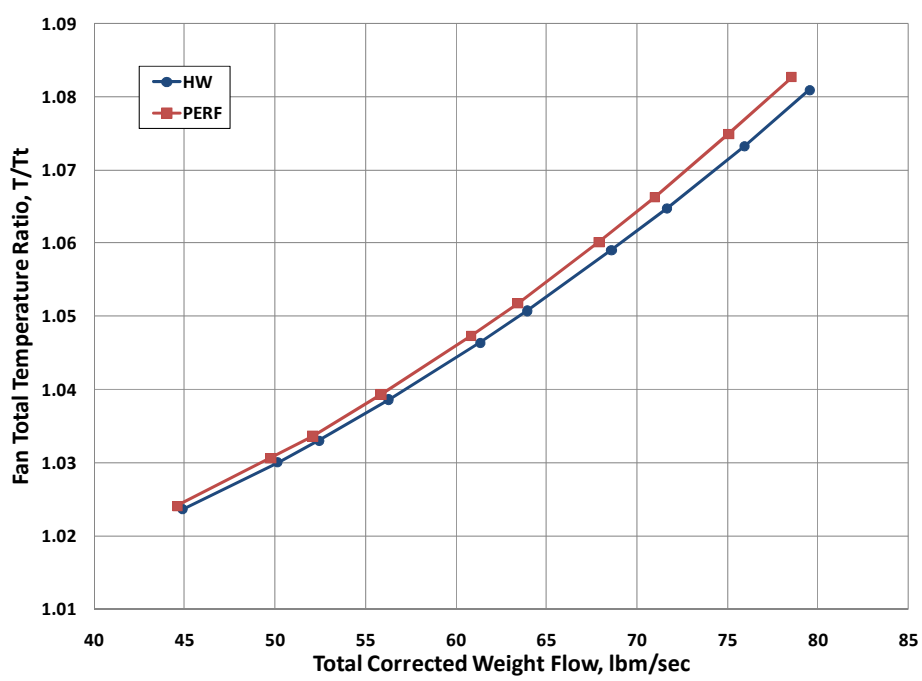

Figure 10. Comparison of fan temperature rise between HW and PERF rubstrips.

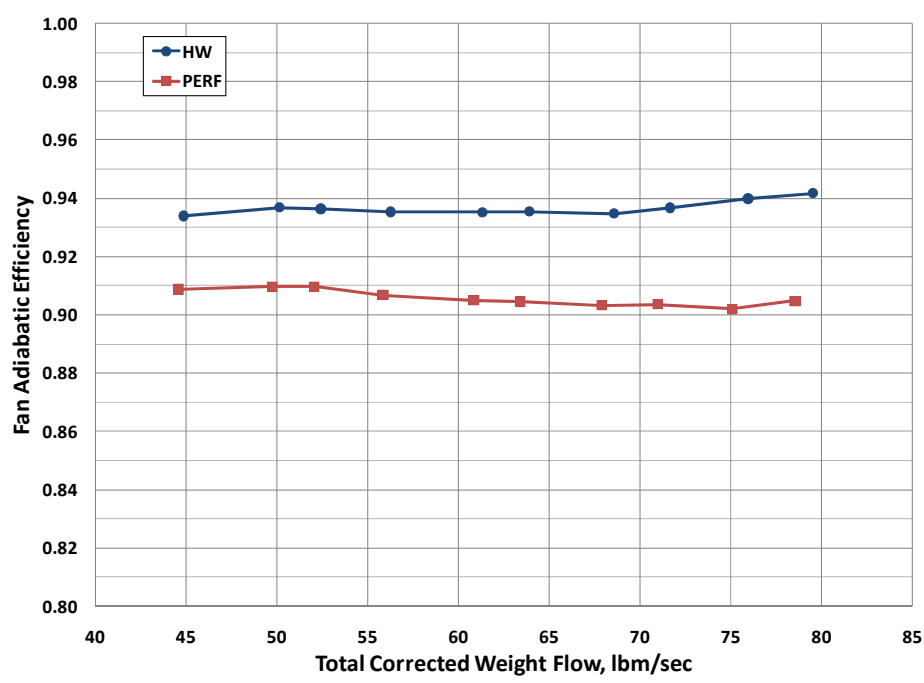

Figure 11. Comparison of fan adiabatic efficiency between HW and PERF rubstrips.

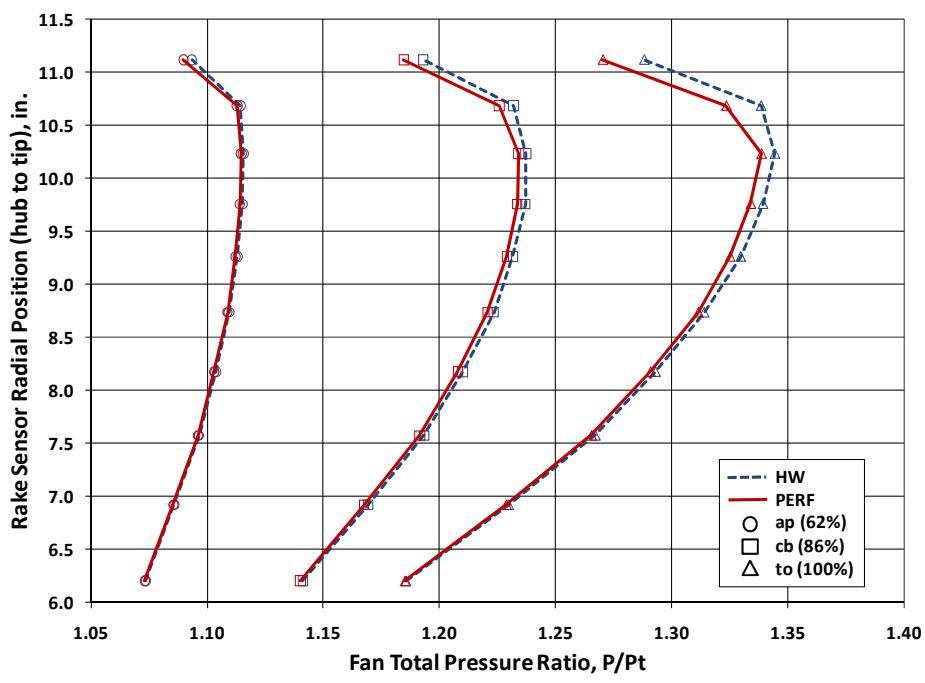

Figure 12. Comparison of radial fan pressure profiles between HW and PERF rubstrips. 


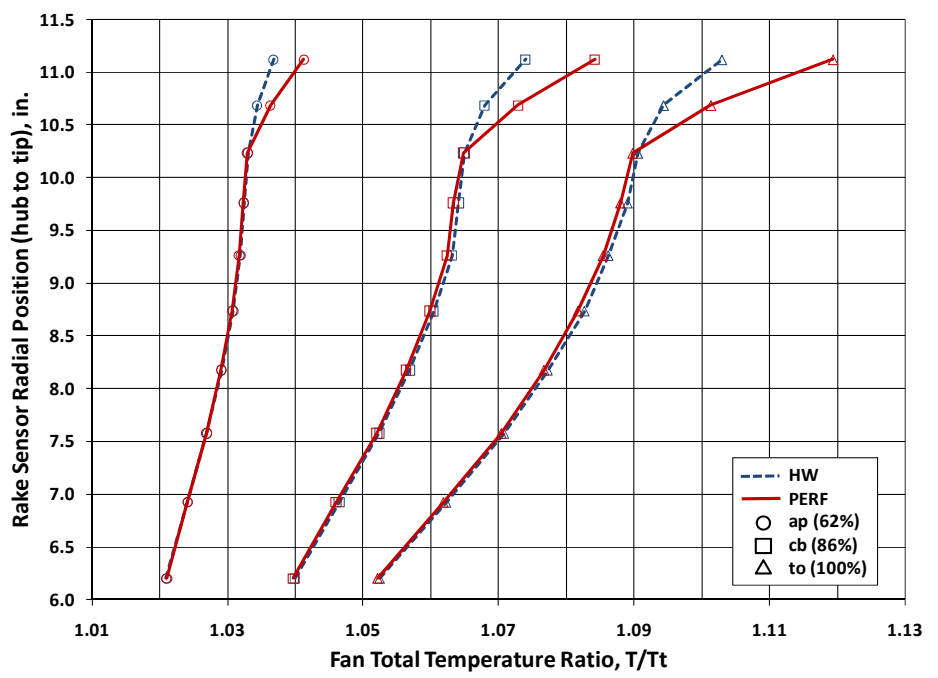

Figure 13. Comparison of radial fan temperature profiles between HW and PERF rubstrips.

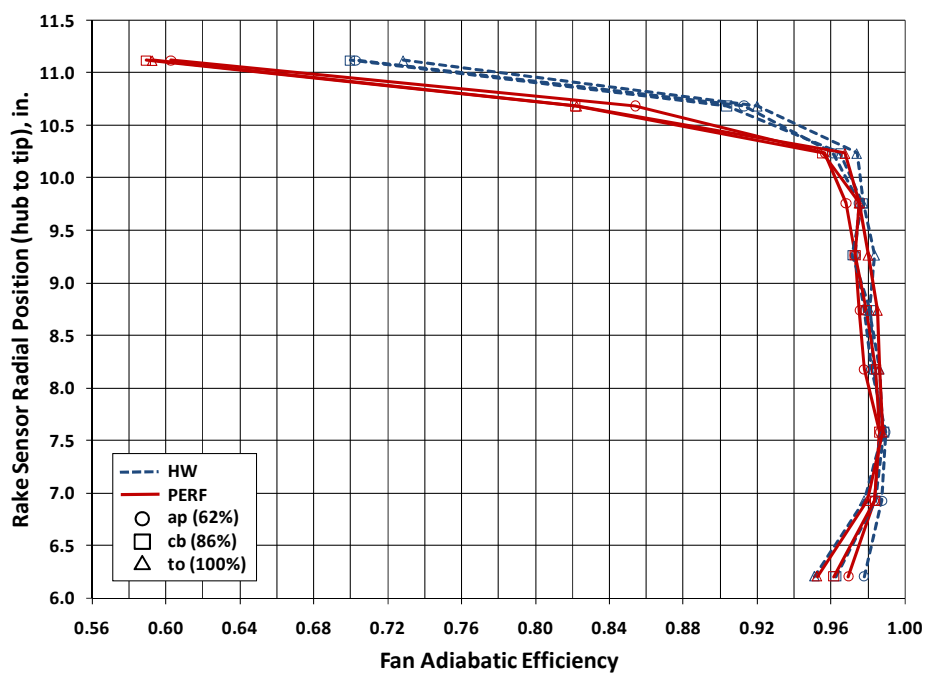

Figure 14. Comparison of radial fan adiabatic efficiency profiles between HW and PERF rubstrips.

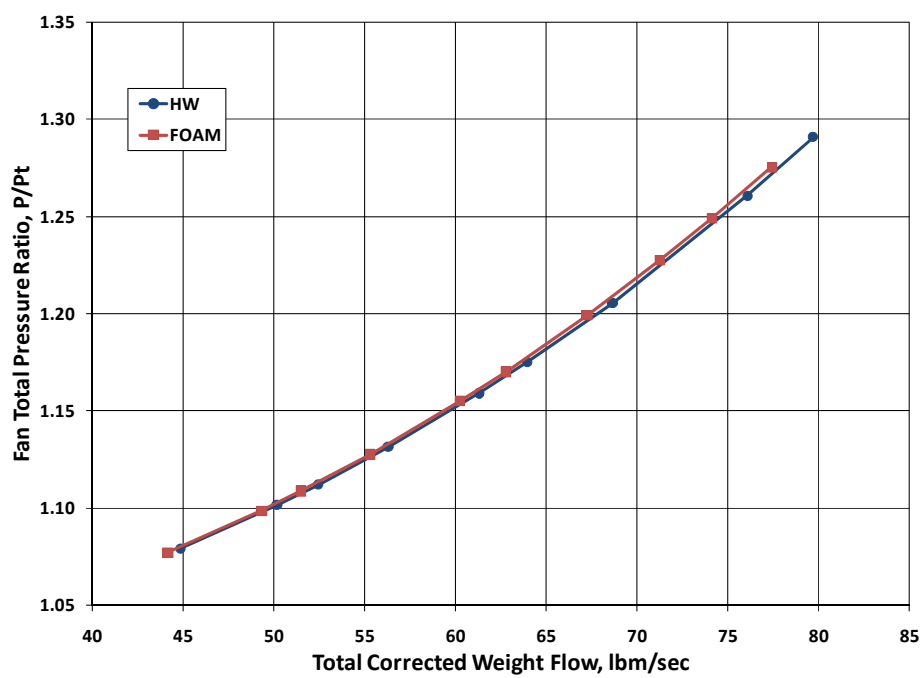

Figure 15. Comparison of fan pressure rise between HW and FOAM rubstrips. 


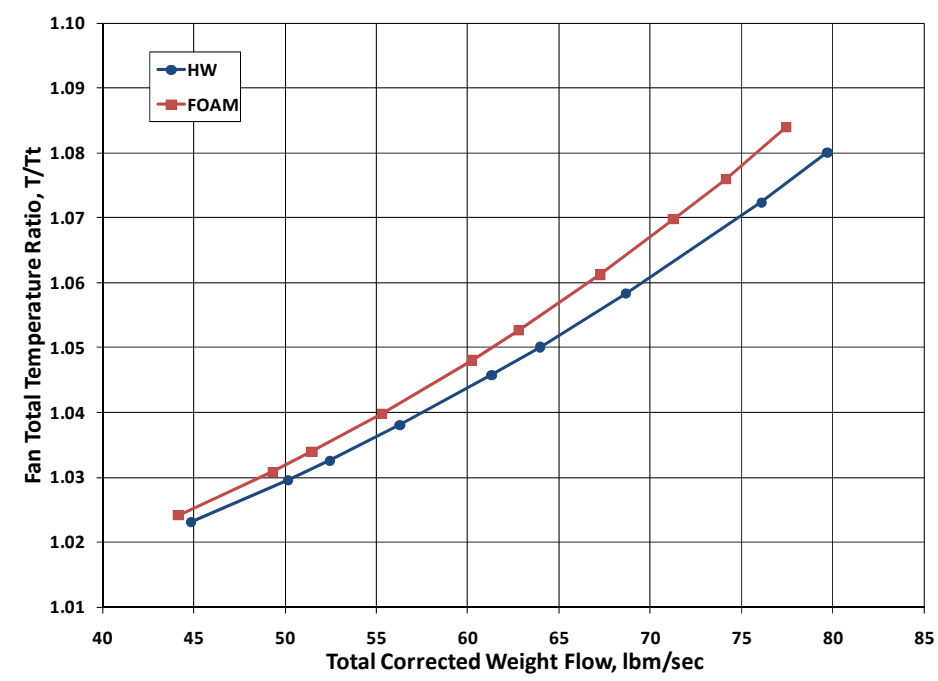

Figure 16. Comparison of fan temperature rise between HW and FOAM rubstrips.

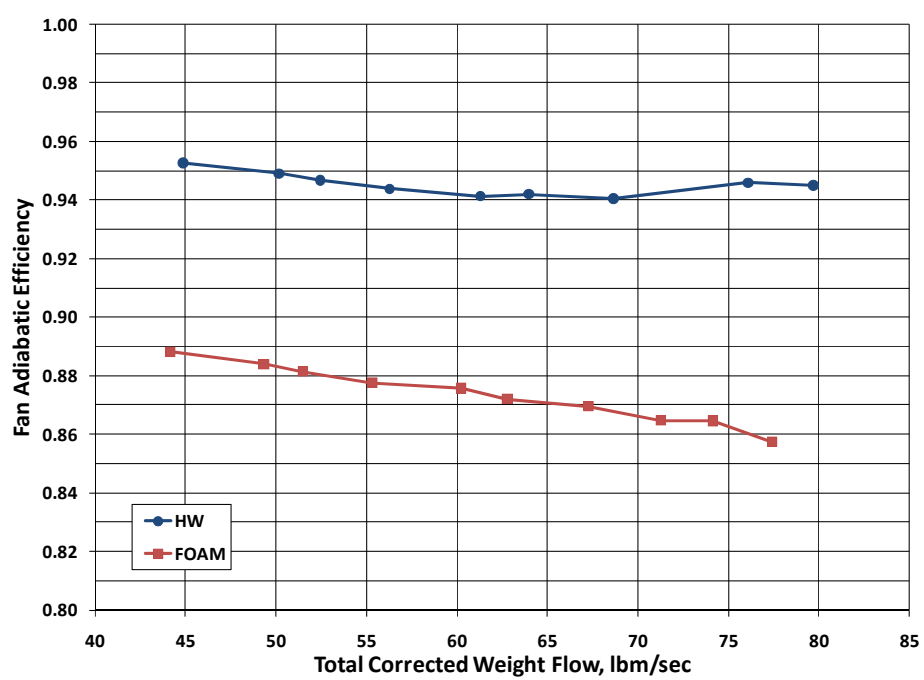

Figure 17. Comparison of fan adiabatic efficiency between HW and FOAM rubstrips.

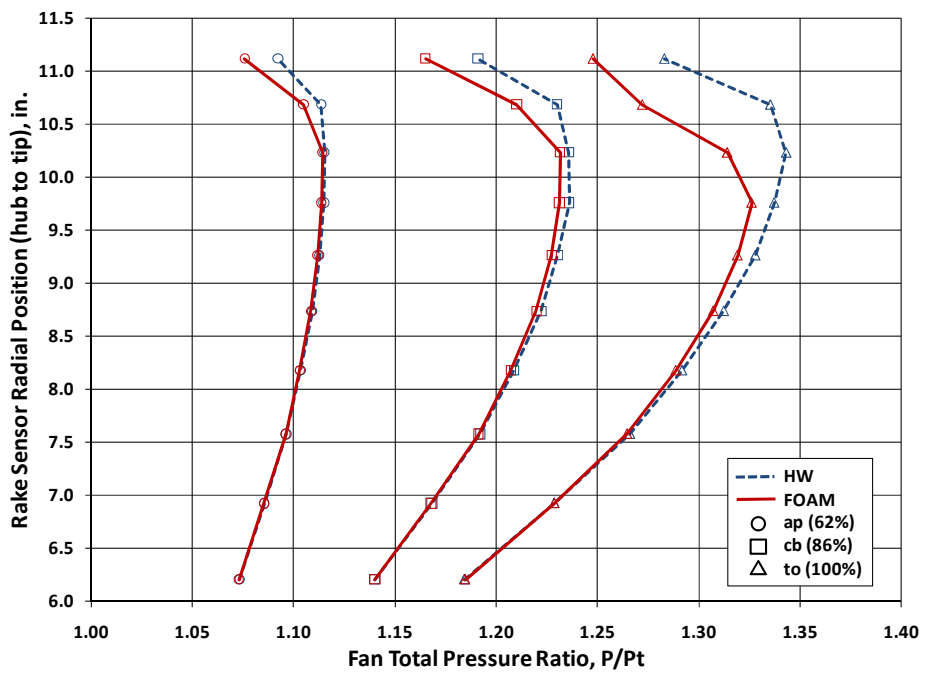

Figure 18. Comparison of fan pressure profiles between HW and FOAM rubstrips. 


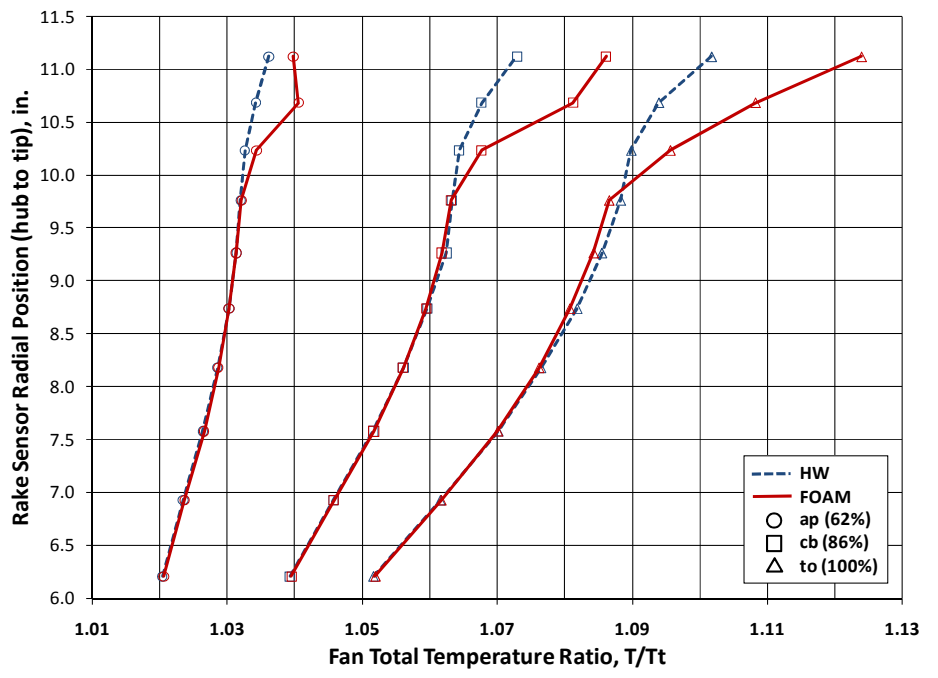

Figure 19. Comparison of fan temperature profiles between HW and FOAM rubstrips.

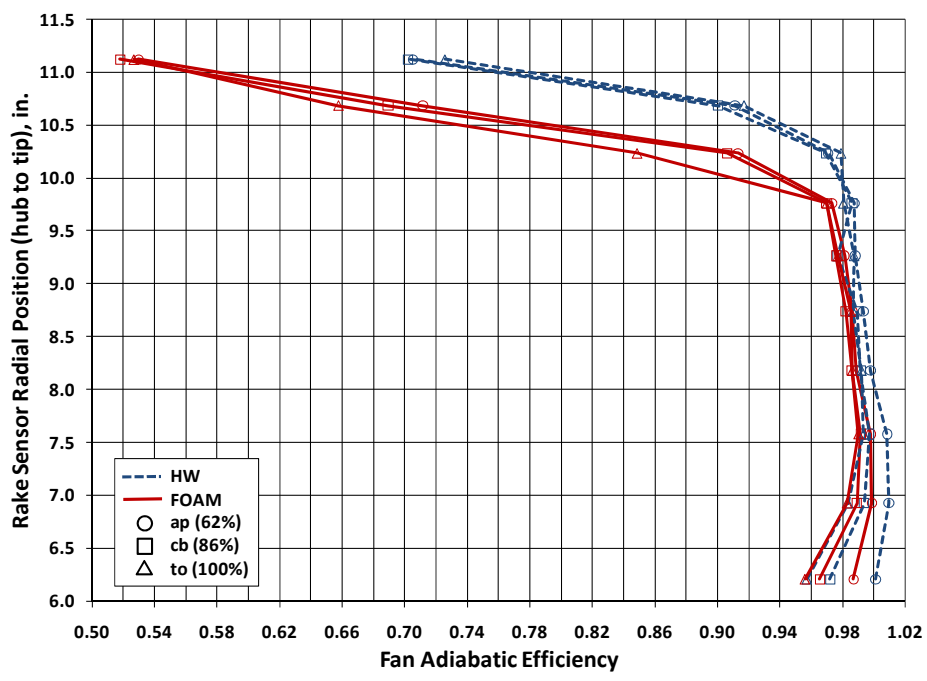

Figure 20. Comparison of fan adiabatic efficiency profiles between HW and FOAM rubstrips.

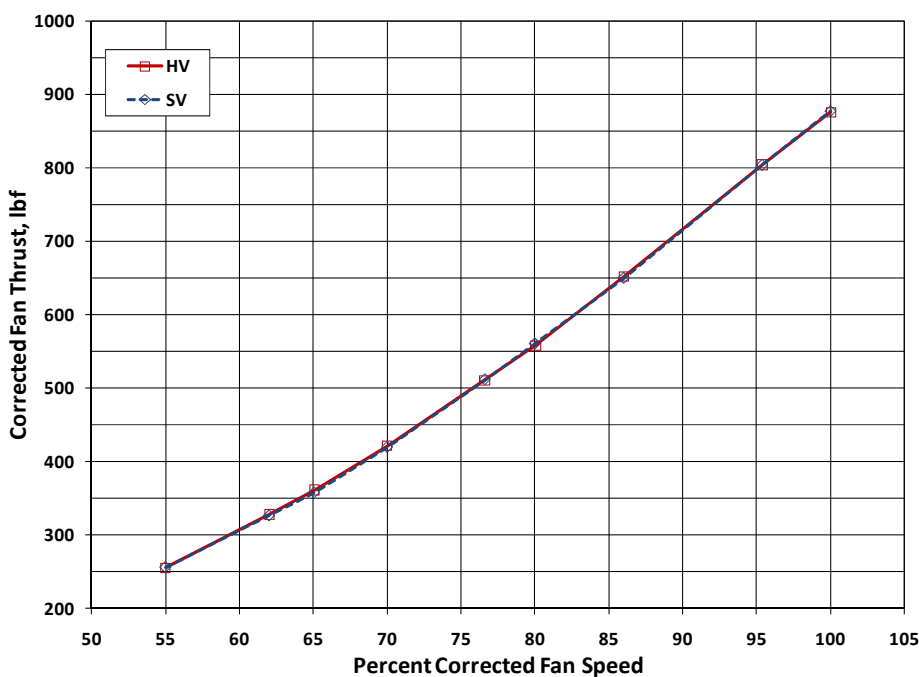

Figure 21. Comparison of fan thrust between $\mathrm{HV}$ and SV stators. 


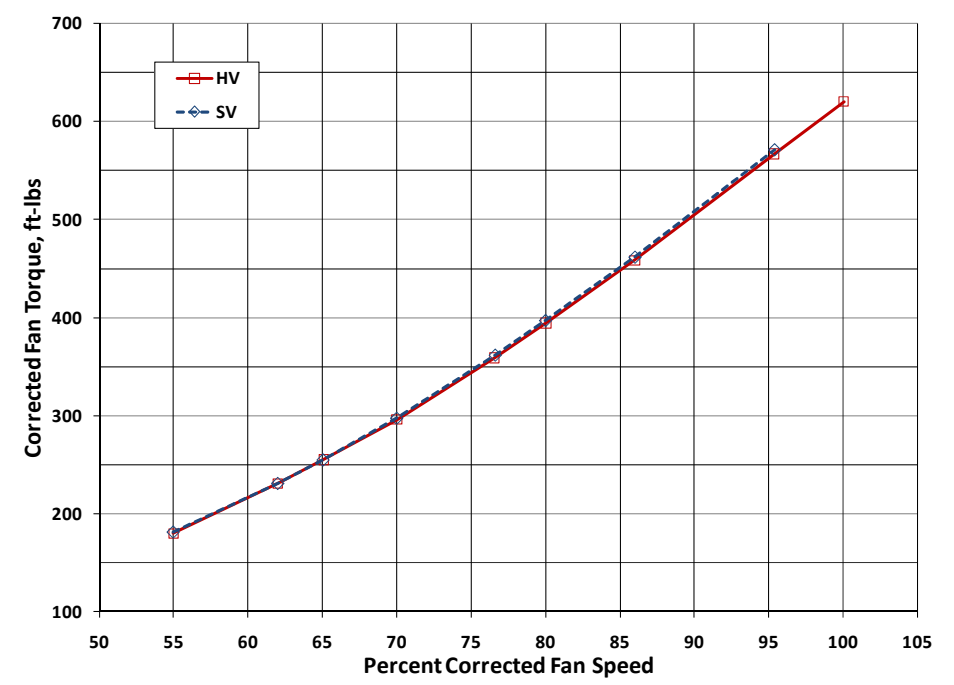

Figure 22. Comparison of fan torque between HV and SV stators.

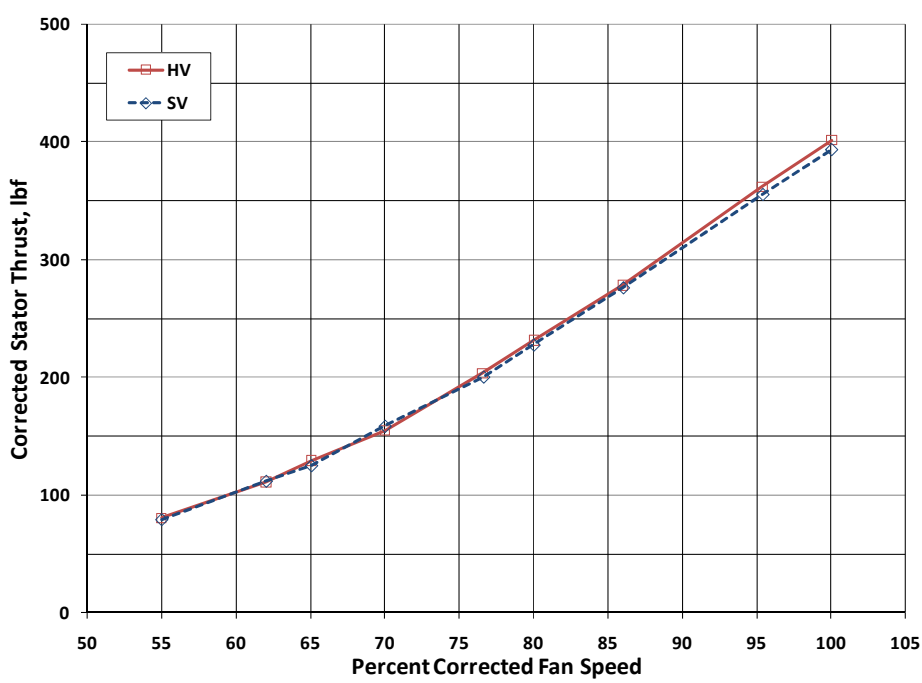

Figure 23. Comparison of stator thrust between HV and SV stators.

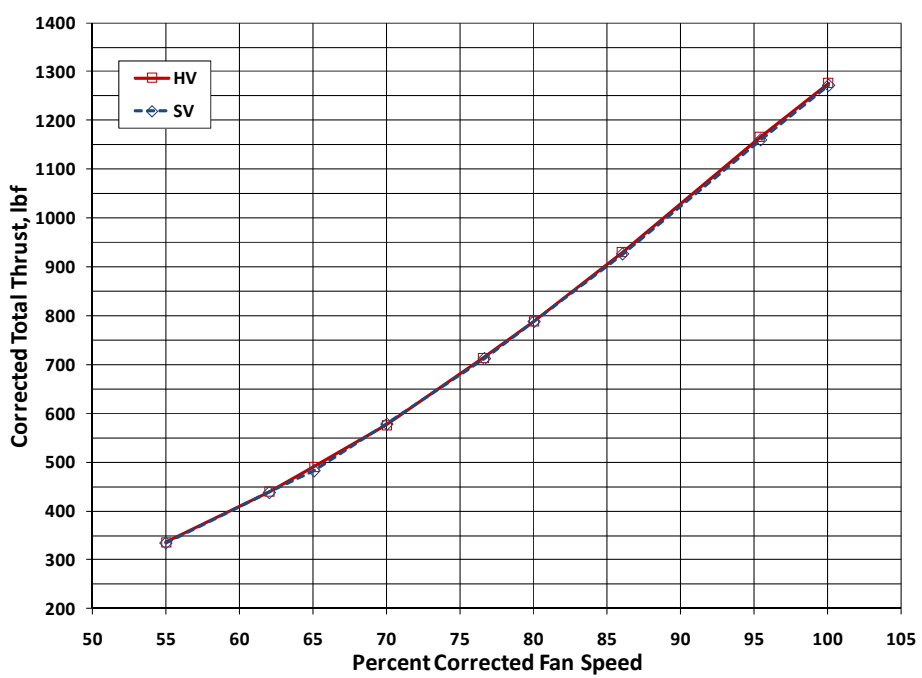

Figure 24. Comparison of total thrust between HV and SV stators. 
Appendix A-Aerodynamic Performance Data

Table 1A. Performance data taken with Hardwall (HW) Rubstrip installed during HW-PERF comparison test

\begin{tabular}{|c|c|c|c|c|}
\hline $\begin{array}{c}\text { Percent } \\
\text { Corrected } \\
\text { Fan } \\
\text { Speed }\end{array}$ & $\begin{array}{c}\text { Corrected } \\
\text { Weight } \\
\text { Flow, } \\
\text { Ibm/sec }\end{array}$ & $\begin{array}{c}\text { Fan } \\
\text { Total } \\
\text { Pressure } \\
\text { Ratio }\end{array}$ & $\begin{array}{c}\text { Fan } \\
\text { Total } \\
\text { Temperature } \\
\text { Ratio }\end{array}$ & $\begin{array}{c}\text { Fan } \\
\text { Adiabatic } \\
\text { Efficiency }\end{array}$ \\
\hline 54.99 & 44.88 & 1.0794 & 1.0236 & 0.9339 \\
61.97 & 50.15 & 1.1021 & 1.0301 & 0.9368 \\
64.99 & 52.44 & 1.1124 & 1.0330 & 0.9364 \\
70.05 & 56.28 & 1.1322 & 1.0386 & 0.9353 \\
76.63 & 61.35 & 1.1602 & 1.0464 & 0.9352 \\
80.04 & 63.93 & 1.1762 & 1.0507 & 0.9355 \\
86.08 & 68.59 & 1.2068 & 1.0590 & 0.9347 \\
90.01 & 71.67 & 1.2288 & 1.0647 & 0.9367 \\
95.44 & 75.96 & 1.2623 & 1.0732 & 0.9399 \\
100.02 & 79.54 & 1.2930 & 1.0809 & 0.9417 \\
\hline
\end{tabular}

Table 1B. Performance data taken with Perforated (PERF) Rubstrip installed during HW-PERF comparison test

\begin{tabular}{|c|c|c|c|c|}
\hline $\begin{array}{c}\text { Percent } \\
\text { Corrected } \\
\text { Fan } \\
\text { Speed }\end{array}$ & $\begin{array}{c}\text { Corrected } \\
\text { Weight } \\
\text { Flow, } \\
\text { Ibm/sec }\end{array}$ & $\begin{array}{c}\text { Fan } \\
\text { Pressure } \\
\text { Ratio }\end{array}$ & $\begin{array}{c}\text { Fan } \\
\text { Temperature } \\
\text { Ratio }\end{array}$ & $\begin{array}{c}\text { Fan } \\
\text { Adiabatic } \\
\text { Efficiency }\end{array}$ \\
\hline 55.03 & 44.61 & 1.0787 & 1.0241 & 0.9088 \\
61.98 & 49.78 & 1.1010 & 1.0306 & 0.9097 \\
64.99 & 52.08 & 1.1112 & 1.0336 & 0.9097 \\
70.01 & 55.86 & 1.1304 & 1.0393 & 0.9067 \\
76.63 & 60.86 & 1.1582 & 1.0474 & 0.9050 \\
80.01 & 63.41 & 1.1737 & 1.0518 & 0.9045 \\
85.99 & 67.92 & 1.2035 & 1.0602 & 0.9033 \\
90.02 & 70.98 & 1.2256 & 1.0662 & 0.9035 \\
95.42 & 75.08 & 1.2571 & 1.0749 & 0.9020 \\
100.04 & 78.54 & 1.2872 & 1.0827 & 0.9048 \\
& & & & \\
\hline
\end{tabular}


Table 2A. Performance data taken with Hardwall (HW) Rubstrip installed during HW-FOAM comparison test

\begin{tabular}{|c|c|c|c|c|}
\hline $\begin{array}{c}\text { Percent } \\
\text { Corrected } \\
\text { Fan } \\
\text { Speed }\end{array}$ & $\begin{array}{c}\text { Corrected } \\
\text { Weight } \\
\text { Flow, } \\
\text { Ibm/sec }\end{array}$ & $\begin{array}{c}\text { Fan } \\
\text { Total } \\
\text { Pressure } \\
\text { Ratio }\end{array}$ & $\begin{array}{c}\text { Fan } \\
\text { Total } \\
\text { Temperature } \\
\text { Ratio }\end{array}$ & $\begin{array}{c}\text { Fan } \\
\text { Adiabatic } \\
\text { Efficiency }\end{array}$ \\
\hline 55.01 & 44.87 & 1.0792 & 1.0231 & 0.9526 \\
61.99 & 50.17 & 1.1016 & 1.0296 & 0.9491 \\
65.03 & 52.45 & 1.1121 & 1.0326 & 0.9468 \\
70.04 & 56.29 & 1.1315 & 1.0381 & 0.9438 \\
76.58 & 61.31 & 1.1591 & 1.0458 & 0.9413 \\
80.02 & 63.97 & 1.1751 & 1.0501 & 0.9420 \\
86.04 & 68.65 & 1.2054 & 1.0583 & 0.9405 \\
95.44 & 76.08 & 1.2606 & 1.0723 & 0.9459 \\
100.07 & 79.69 & 1.2909 & 1.0801 & 0.9450 \\
\hline
\end{tabular}

Table 2B. Performance data taken with Exposed Metal Foam (FOAM) Rubstrip installed during HWFOAM comparison test

\begin{tabular}{|c|c|c|c|c|}
\hline $\begin{array}{c}\text { Percent } \\
\text { Corrected } \\
\text { Fan } \\
\text { Speed }\end{array}$ & $\begin{array}{c}\text { Corrected } \\
\text { Weight } \\
\text { Flow, } \\
\text { Ibm/sec }\end{array}$ & $\begin{array}{c}\text { Fan } \\
\text { Total } \\
\text { Pressure } \\
\text { Ratio }\end{array}$ & $\begin{array}{c}\text { Fan } \\
\text { Total } \\
\text { Temperature } \\
\text { Ratio }\end{array}$ & $\begin{array}{c}\text { Fan } \\
\text { Adiabatic } \\
\text { Efficiency }\end{array}$ \\
\hline 55.02 & 44.16 & 1.0771 & 1.0241 & 0.8881 \\
61.97 & 49.32 & 1.0986 & 1.0308 & 0.8839 \\
65.01 & 51.48 & 1.1088 & 1.0340 & 0.8814 \\
70.00 & 55.32 & 1.1275 & 1.0398 & 0.8776 \\
76.63 & 60.24 & 1.1551 & 1.0480 & 0.8757 \\
80.04 & 62.78 & 1.1701 & 1.0527 & 0.8720 \\
86.07 & 67.25 & 1.1991 & 1.0612 & 0.8695 \\
91.54 & 71.27 & 1.2276 & 1.0698 & 0.8647 \\
95.45 & 74.13 & 1.2492 & 1.0759 & 0.8646 \\
100.11 & 77.42 & 1.2753 & 1.0839 & 0.8574 \\
& & & & \\
\hline
\end{tabular}


Table 3A. Performance profile data taken with Hardwall (HW) Rubstrip installed during HW-PERF comparison test

\begin{tabular}{|c|c|c|c|c|c|c|c|c|c|c|c|}
\hline $\begin{array}{l}\text { Percent Corrected Fan Speed } \\
\text { Corrected Weight Flow, Ibm/sec }\end{array}$ & & $\begin{array}{l}54.99 \\
44.88\end{array}$ & $\begin{array}{l}61.97 \\
50.15\end{array}$ & $\begin{array}{l}64.99 \\
52.44\end{array}$ & $\begin{array}{l}70.05 \\
56.28\end{array}$ & $\begin{array}{l}76.63 \\
61.35\end{array}$ & $\begin{array}{l}80.04 \\
63.93\end{array}$ & $\begin{array}{l}86.08 \\
68.59\end{array}$ & $\begin{array}{l}90.01 \\
71.67\end{array}$ & $\begin{array}{l}95.44 \\
75.96\end{array}$ & $\begin{array}{c}100.02 \\
79.54\end{array}$ \\
\hline & $\begin{array}{l}\text { Radial } \\
\text { Pos, in. }\end{array}$ & \multicolumn{10}{|c|}{ Fan Total Pressure Ratio } \\
\hline & 6.204 & 1.0576 & 1.0736 & 1.0812 & 1.0947 & 1.1129 & 1.1228 & 1.1411 & 1.1534 & 1.1709 & 1.1858 \\
\hline & 6.924 & 1.0674 & 1.0859 & 1.0947 & 1.1105 & 1.1332 & 1.1457 & 1.1694 & 1.1859 & 1.2093 & 1.2299 \\
\hline & 7.577 & 1.0755 & 1.0965 & 1.1066 & 1.1248 & 1.1509 & 1.1657 & 1.1934 & 1.2130 & 1.2421 & 1.2672 \\
\hline & 8.177 & 1.0807 & 1.1036 & 1.1143 & 1.1344 & 1.1631 & 1.1791 & 1.2100 & 1.2316 & 1.2639 & 1.2931 \\
\hline & 8.737 & 1.0852 & 1.1095 & 1.1209 & 1.1424 & 1.1727 & 1.1902 & 1.2234 & 1.2466 & 1.2827 & 1.3139 \\
\hline & 9.263 & 1.0877 & 1.1130 & 1.1243 & 1.1468 & 1.1787 & 1.1966 & 1.2316 & 1.2569 & 1.2938 & 1.3297 \\
\hline & 9.760 & 1.0891 & 1.1152 & 1.1266 & 1.1494 & 1.1818 & 1.2003 & 1.2371 & 1.2618 & 1.3025 & 1.3392 \\
\hline & 10.233 & 1.0895 & 1.1155 & 1.1275 & 1.1501 & 1.1822 & 1.2018 & 1.2372 & 1.2650 & 1.3052 & 1.3444 \\
\hline & 10.685 & 1.0889 & 1.1143 & 1.1253 & 1.1476 & 1.1784 & 1.1965 & 1.2320 & 1.2583 & 1.2999 & 1.3385 \\
\hline & 11.119 & 1.0724 & 1.0935 & 1.1026 & 1.1214 & 1.1477 & 1.1632 & 1.1931 & 1.2157 & 1.2527 & 1.2882 \\
\hline & \multicolumn{11}{|c|}{ Fan Total Temperature Ratio } \\
\hline & 6.204 & 1.0166 & 1.0210 & 1.0231 & 1.0268 & 1.0320 & 1.0347 & 1.0399 & 1.0433 & 1.0481 & 1.0525 \\
\hline & 6.924 & 1.0191 & 1.0241 & 1.0265 & 1.0308 & 1.0368 & 1.0401 & 1.0465 & 1.0507 & 1.0570 & 1.0623 \\
\hline & 7.577 & 1.0213 & 1.0270 & 1.0296 & 1.0345 & 1.0413 & 1.0452 & 1.0524 & 1.0574 & 1.0646 & 1.0708 \\
\hline & 8.177 & 1.0230 & 1.0291 & 1.0320 & 1.0374 & 1.0448 & 1.0490 & 1.0569 & 1.0624 & 1.0704 & 1.0773 \\
\hline & 8.737 & 1.0241 & 1.0308 & 1.0338 & 1.0395 & 1.0475 & 1.0520 & 1.0604 & 1.0663 & 1.0748 & 1.0827 \\
\hline & 9.263 & 1.0250 & 1.0319 & 1.0349 & 1.0409 & 1.0493 & 1.0540 & 1.0631 & 1.0690 & 1.0783 & 1.0862 \\
\hline & 9.760 & 1.0255 & 1.0325 & 1.0358 & 1.0417 & 1.0502 & 1.0553 & 1.0642 & 1.0708 & 1.0801 & 1.0891 \\
\hline & 10.233 & 1.0260 & 1.0330 & 1.0361 & 1.0423 & 1.0508 & 1.0556 & 1.0650 & 1.0716 & 1.0816 & 1.0906 \\
\hline & 10.685 & 1.0270 & 1.0344 & 1.0378 & 1.0443 & 1.0533 & 1.0581 & 1.0680 & 1.0746 & 1.0849 & 1.0944 \\
\hline & 11.119 & 1.0287 & 1.0368 & 1.0406 & 1.0478 & 1.0577 & 1.0633 & 1.0740 & 1.0813 & 1.0924 & 1.1030 \\
\hline & \multicolumn{11}{|c|}{ Fan Adiabatic Efficiency } \\
\hline & 6.204 & 0.9733 & 0.9778 & 0.9775 & 0.9763 & 0.9699 & 0.9684 & 0.9625 & 0.9608 & 0.9594 & 0.9510 \\
\hline & 6.924 & 0.9823 & 0.9874 & 0.9897 & 0.9880 & 0.9891 & 0.9873 & 0.9840 & 0.9842 & 0.9791 & 0.9779 \\
\hline & 7.577 & 0.9866 & 0.9894 & 0.9918 & 0.9898 & 0.9912 & 0.9902 & 0.9884 & 0.9887 & 0.9897 & 0.9881 \\
\hline & 8.177 & 0.9748 & 0.9817 & 0.9824 & 0.9805 & 0.9838 & 0.9833 & 0.9831 & 0.9835 & 0.9828 & 0.9860 \\
\hline & 8.737 & 0.9801 & 0.9782 & 0.9819 & 0.9812 & 0.9810 & 0.9812 & 0.9813 & 0.9806 & 0.9858 & 0.9808 \\
\hline & 9.263 & 0.9741 & 0.9732 & 0.9752 & 0.9750 & 0.9753 & 0.9750 & 0.9715 & 0.9783 & 0.9748 & 0.9836 \\
\hline & 9.760 & 0.9683 & 0.9753 & 0.9681 & 0.9724 & 0.9747 & 0.9681 & 0.9769 & 0.9698 & 0.9788 & 0.9772 \\
\hline & 10.233 & 0.9544 & 0.9609 & 0.9666 & 0.9630 & 0.9645 & 0.9707 & 0.9650 & 0.9698 & 0.9693 & 0.9738 \\
\hline & 10.685 & 0.9125 & 0.9128 & 0.9075 & 0.9058 & 0.9014 & 0.9056 & 0.9035 & 0.9099 & 0.9167 & 0.9200 \\
\hline & 11.119 & 0.7016 & 0.7026 & 0.6977 & 0.6964 & 0.6958 & 0.6973 & 0.6996 & 0.7059 & 0.7194 & 0.7284 \\
\hline
\end{tabular}


Table 3B. Performance profile data taken with Perforated (PERF) Rubstrip installed during HW-PERF comparison test

\begin{tabular}{|c|c|c|c|c|c|c|c|c|c|c|c|}
\hline $\begin{array}{l}\text { Percent Corrected Fan Speed } \\
\text { Corrected Weight Flow, Ibm/sec }\end{array}$ & & $\begin{array}{l}55.03 \\
44.61\end{array}$ & $\begin{array}{l}61.98 \\
49.78\end{array}$ & $\begin{array}{l}64.99 \\
52.08\end{array}$ & $\begin{array}{l}70.01 \\
55.86\end{array}$ & $\begin{array}{l}76.63 \\
60.86\end{array}$ & $\begin{array}{l}80.01 \\
63.41\end{array}$ & $\begin{array}{l}85.99 \\
67.92\end{array}$ & $\begin{array}{l}90.02 \\
70.98\end{array}$ & $\begin{array}{l}95.42 \\
75.08\end{array}$ & $\begin{array}{c}100.04 \\
78.54\end{array}$ \\
\hline & $\begin{array}{l}\text { Radial } \\
\text { Pos, in. }\end{array}$ & \multicolumn{10}{|c|}{ Fan Total Pressure Ratio } \\
\hline & 6.204 & 1.0574 & 1.0732 & 1.0806 & 1.0937 & 1.1123 & 1.1221 & 1.1401 & 1.1528 & 1.1697 & 1.1850 \\
\hline & 6.924 & 1.0671 & 1.0854 & 1.0941 & 1.1096 & 1.1322 & 1.1444 & 1.1677 & 1.1845 & 1.2080 & 1.2287 \\
\hline & 7.577 & 1.0752 & 1.0961 & 1.1060 & 1.1239 & 1.1499 & 1.1644 & 1.1914 & 1.2117 & 1.2399 & 1.2654 \\
\hline & 8.177 & 1.0804 & 1.1030 & 1.1137 & 1.1333 & 1.1619 & 1.1775 & 1.2079 & 1.2297 & 1.2622 & 1.2907 \\
\hline & 8.737 & 1.0847 & 1.1088 & 1.1200 & 1.1409 & 1.1712 & 1.1883 & 1.2207 & 1.2446 & 1.2789 & 1.3113 \\
\hline & 9.263 & 1.0872 & 1.1122 & 1.1234 & 1.1453 & 1.1770 & 1.1945 & 1.2290 & 1.2542 & 1.2907 & 1.3250 \\
\hline & 9.760 & 1.0884 & 1.1141 & 1.1257 & 1.1478 & 1.1801 & 1.1984 & 1.2335 & 1.2592 & 1.2975 & 1.3339 \\
\hline & 10.233 & 1.0890 & 1.1147 & 1.1263 & 1.1486 & 1.1806 & 1.1990 & 1.2340 & 1.2618 & 1.3006 & 1.3385 \\
\hline & 10.685 & 1.0882 & 1.1130 & 1.1238 & 1.1451 & 1.1752 & 1.1921 & 1.2257 & 1.2513 & 1.2869 & 1.3234 \\
\hline & 11.119 & 1.0701 & 1.0898 & 1.0985 & 1.1159 & 1.1416 & 1.1565 & 1.1847 & 1.2063 & 1.2371 & 1.2702 \\
\hline \multicolumn{12}{|c|}{ Fan Total Temperature Ratio } \\
\hline & 6.204 & 1.0166 & 1.0210 & 1.0230 & 1.0268 & 1.0320 & 1.0347 & 1.0397 & 1.0432 & 1.0479 & 1.0522 \\
\hline & 6.924 & 1.0192 & 1.0241 & 1.0264 & 1.0307 & 1.0367 & 1.0400 & 1.0460 & 1.0505 & 1.0566 & 1.0619 \\
\hline & 7.577 & 1.0213 & 1.0269 & 1.0295 & 1.0344 & 1.0413 & 1.0450 & 1.0520 & 1.0570 & 1.0643 & 1.0704 \\
\hline & 8.177 & 1.0230 & 1.0291 & 1.0318 & 1.0372 & 1.0446 & 1.0487 & 1.0563 & 1.0619 & 1.0697 & 1.0767 \\
\hline & 8.737 & 1.0242 & 1.0307 & 1.0336 & 1.0393 & 1.0472 & 1.0516 & 1.0599 & 1.0658 & 1.0742 & 1.0817 \\
\hline & 9.263 & 1.0249 & 1.0317 & 1.0348 & 1.0407 & 1.0490 & 1.0537 & 1.0624 & 1.0684 & 1.0775 & 1.0854 \\
\hline & 9.760 & 1.0255 & 1.0324 & 1.0355 & 1.0415 & 1.0499 & 1.0547 & 1.0634 & 1.0703 & 1.0791 & 1.0880 \\
\hline & 10.233 & 1.0259 & 1.0329 & 1.0360 & 1.0422 & 1.0507 & 1.0553 & 1.0648 & 1.0711 & 1.0812 & 1.0898 \\
\hline & 10.685 & 1.0283 & 1.0364 & 1.0400 & 1.0470 & 1.0569 & 1.0623 & 1.0729 & 1.0806 & 1.0916 & 1.1013 \\
\hline & 11.119 & 1.0321 & 1.0413 & 1.0456 & 1.0536 & 1.0652 & 1.0718 & 1.0842 & 1.0935 & 1.1071 & 1.1193 \\
\hline \multicolumn{12}{|c|}{ Fan Adiabatic Efficiency } \\
\hline & 6.204 & 0.9665 & 0.9693 & 0.9749 & 0.9685 & 0.9645 & 0.9647 & 0.9615 & 0.9597 & 0.9570 & 0.9524 \\
\hline & 6.924 & 0.9773 & 0.9832 & 0.9864 & 0.9829 & 0.9837 & 0.9827 & 0.9837 & 0.9824 & 0.9802 & 0.9797 \\
\hline & 7.577 & 0.9808 & 0.9863 & 0.9892 & 0.9868 & 0.9867 & 0.9880 & 0.9863 & 0.9890 & 0.9861 & 0.9877 \\
\hline & 8.177 & 0.9723 & 0.9777 & 0.9810 & 0.9788 & 0.9813 & 0.9807 & 0.9841 & 0.9825 & 0.9874 & 0.9860 \\
\hline & 8.737 & 0.9732 & 0.9754 & 0.9796 & 0.9773 & 0.9782 & 0.9797 & 0.9790 & 0.9802 & 0.9810 & 0.9852 \\
\hline & 9.263 & 0.9725 & 0.9729 & 0.9713 & 0.9716 & 0.9720 & 0.9701 & 0.9729 & 0.9767 & 0.9763 & 0.9800 \\
\hline & 9.760 & 0.9608 & 0.9681 & 0.9695 & 0.9686 & 0.9717 & 0.9704 & 0.9755 & 0.9680 & 0.9762 & 0.9752 \\
\hline & 10.233 & 0.9522 & 0.9566 & 0.9610 & 0.9576 & 0.9573 & 0.9621 & 0.9554 & 0.9661 & 0.9598 & 0.9676 \\
\hline & 10.685 & 0.8628 & 0.8539 & 0.8469 & 0.8406 & 0.8297 & 0.8267 & 0.8216 & 0.8210 & 0.8161 & 0.8225 \\
\hline & 11.119 & 0.6082 & 0.6027 & 0.5965 & 0.5945 & 0.5921 & 0.5909 & 0.5892 & 0.5890 & 0.5852 & 0.5928 \\
\hline
\end{tabular}


Table 4A. Performance profile data taken with Hardwall (HW) Rubstrip installed during HW-FOAM comparison test

\begin{tabular}{|c|c|c|c|c|c|c|c|c|c|c|}
\hline $\begin{array}{l}\text { Percent Corrected Fan Speed } \\
\text { Corrected Weight Flow, Ibm/sec }\end{array}$ & & $\begin{array}{l}55.01 \\
44.87\end{array}$ & $\begin{array}{l}61.99 \\
50.17\end{array}$ & $\begin{array}{l}65.03 \\
52.45\end{array}$ & $\begin{array}{l}70.04 \\
56.29\end{array}$ & $\begin{array}{l}76.58 \\
61.31\end{array}$ & $\begin{array}{l}80.02 \\
63.97\end{array}$ & $\begin{array}{l}86.04 \\
68.65 \\
\end{array}$ & $\begin{array}{l}95.44 \\
76.08 \\
\end{array}$ & $\begin{array}{c}100.07 \\
79.69\end{array}$ \\
\hline & $\begin{array}{l}\text { Radial } \\
\text { Pos, in. }\end{array}$ & \multicolumn{9}{|c|}{ Fan Total Pressure Ratio } \\
\hline & 6.204 & 1.0575 & 1.0733 & 1.0810 & 1.0941 & 1.1123 & 1.1221 & 1.1401 & 1.1691 & 1.1841 \\
\hline & 6.924 & 1.0672 & 1.0855 & 1.0945 & 1.1099 & 1.1324 & 1.1448 & 1.1683 & 1.2081 & 1.2285 \\
\hline & 7.577 & 1.0754 & 1.0963 & 1.1064 & 1.1242 & 1.1500 & 1.1647 & 1.1921 & 1.2408 & 1.2660 \\
\hline & 8.177 & 1.0806 & 1.1034 & 1.1142 & 1.1339 & 1.1622 & 1.1781 & 1.2086 & 1.2628 & 1.2917 \\
\hline & 8.737 & 1.0850 & 1.1092 & 1.1208 & 1.1418 & 1.1717 & 1.1892 & 1.2221 & 1.2809 & 1.3123 \\
\hline & 9.263 & 1.0875 & 1.1127 & 1.1242 & 1.1462 & 1.1777 & 1.1956 & 1.2301 & 1.2925 & 1.3279 \\
\hline & 9.760 & 1.0891 & 1.1149 & 1.1265 & 1.1488 & 1.1809 & 1.1996 & 1.2361 & 1.3009 & 1.3372 \\
\hline & 10.233 & 1.0895 & 1.1153 & 1.1274 & 1.1497 & 1.1814 & 1.2009 & 1.2358 & 1.3040 & 1.3431 \\
\hline & 10.685 & 1.0885 & 1.1136 & 1.1246 & 1.1466 & 1.1768 & 1.1947 & 1.2300 & 1.2977 & 1.3353 \\
\hline & 11.119 & 1.0715 & 1.0922 & 1.1016 & 1.1200 & 1.1459 & 1.1612 & 1.1909 & 1.2497 & 1.2830 \\
\hline & & \multicolumn{9}{|c|}{ Fan Total Temperature Ratio } \\
\hline & 6.204 & 1.0160 & 1.0204 & 1.0226 & 1.0263 & 1.0315 & 1.0341 & 1.0393 & 1.0470 & 1.0517 \\
\hline & 6.924 & 1.0185 & 1.0235 & 1.0259 & 1.0302 & 1.0362 & 1.0395 & 1.0457 & 1.0560 & 1.0616 \\
\hline & 7.577 & 1.0207 & 1.0264 & 1.0291 & 1.0339 & 1.0407 & 1.0445 & 1.0516 & 1.0636 & 1.0702 \\
\hline & 8.177 & 1.0224 & 1.0286 & 1.0315 & 1.0369 & 1.0441 & 1.0483 & 1.0561 & 1.0694 & 1.0765 \\
\hline & 8.737 & 1.0236 & 1.0303 & 1.0333 & 1.0389 & 1.0469 & 1.0513 & 1.0596 & 1.0739 & 1.0818 \\
\hline & 9.263 & 1.0244 & 1.0314 & 1.0345 & 1.0404 & 1.0487 & 1.0533 & 1.0624 & 1.0774 & 1.0855 \\
\hline & 9.760 & 1.0250 & 1.0320 & 1.0353 & 1.0412 & 1.0496 & 1.0546 & 1.0633 & 1.0792 & 1.0883 \\
\hline & 10.233 & 1.0256 & 1.0326 & 1.0357 & 1.0419 & 1.0503 & 1.0549 & 1.0643 & 1.0810 & 1.0898 \\
\hline & 10.685 & 1.0268 & 1.0343 & 1.0378 & 1.0441 & 1.0531 & 1.0579 & 1.0677 & 1.0845 & 1.0939 \\
\hline & 11.119 & 1.0281 & 1.0362 & 1.0400 & 1.0470 & 1.0568 & 1.0623 & 1.0729 & 1.0913 & 1.1017 \\
\hline & & \multicolumn{9}{|c|}{ Fan Adiabatic Efficiency } \\
\hline & 6.204 & 1.0080 & 1.0012 & 0.9964 & 0.9895 & 0.9806 & 0.9798 & 0.9719 & 0.9707 & 0.9571 \\
\hline & 6.924 & 1.0137 & 1.0096 & 1.0070 & 1.0016 & 0.9993 & 0.9973 & 0.9938 & 0.9910 & 0.9835 \\
\hline & 7.577 & 1.0133 & 1.0085 & 1.0059 & 1.0026 & 1.0007 & 1.0003 & 0.9971 & 0.9999 & 0.9936 \\
\hline & 8.177 & 0.9998 & 0.9978 & 0.9971 & 0.9919 & 0.9940 & 0.9920 & 0.9915 & 0.9937 & 0.9922 \\
\hline & 8.737 & 0.9997 & 0.9933 & 0.9957 & 0.9924 & 0.9888 & 0.9895 & 0.9892 & 0.9913 & 0.9867 \\
\hline & 9.263 & 0.9926 & 0.9880 & 0.9869 & 0.9848 & 0.9836 & 0.9825 & 0.9767 & 0.9832 & 0.9874 \\
\hline & 9.760 & 0.9869 & 0.9875 & 0.9799 & 0.9815 & 0.9808 & 0.9772 & 0.9861 & 0.9859 & 0.9806 \\
\hline & 10.233 & 0.9702 & 0.9709 & 0.9764 & 0.9714 & 0.9705 & 0.9785 & 0.9694 & 0.9725 & 0.9791 \\
\hline & 10.685 & 0.9159 & 0.9112 & 0.9040 & 0.9038 & 0.8959 & 0.8998 & 0.9006 & 0.9150 & 0.9170 \\
\hline & 11.119 & 0.7093 & 0.7055 & 0.7014 & 0.7000 & 0.6986 & 0.7001 & 0.7021 & 0.7199 & 0.7256 \\
\hline
\end{tabular}


Table 4B. Performance profile data taken with Exposed Metal Foam (FOAM) Rubstrip installed during HW-FOAM comparison test

\begin{tabular}{|c|c|c|c|c|c|c|c|c|c|c|c|}
\hline $\begin{array}{l}\text { Percent Corrected Fan Speed } \\
\text { Corrected Weight Flow, Ibm/sec }\end{array}$ & & $\begin{array}{l}55.02 \\
44.16 \\
\end{array}$ & $\begin{array}{l}61.97 \\
49.32 \\
\end{array}$ & $\begin{array}{l}65.01 \\
51.48\end{array}$ & $\begin{array}{l}70.00 \\
55.32 \\
\end{array}$ & $\begin{array}{l}76.63 \\
60.24 \\
\end{array}$ & $\begin{array}{l}80.04 \\
62.78 \\
\end{array}$ & $\begin{array}{l}86.07 \\
67.25 \\
\end{array}$ & $\begin{array}{l}91.54 \\
71.27\end{array}$ & $\begin{array}{l}95.45 \\
74.13 \\
\end{array}$ & $\begin{array}{l}100.11 \\
77.42 \\
\end{array}$ \\
\hline & $\begin{array}{l}\text { Radial } \\
\text { Pos, in. }\end{array}$ & & \multicolumn{8}{|c|}{ Fan Total Pressure Ratio } & \\
\hline & 6.204 & 1.0573 & 1.0730 & 1.0807 & 1.0935 & 1.1121 & 1.1220 & 1.1401 & 1.1570 & 1.1690 & 1.1847 \\
\hline & 6.924 & 1.0671 & 1.0853 & 1.0941 & 1.1093 & 1.1319 & 1.1441 & 1.1677 & 1.1909 & 1.2079 & 1.2288 \\
\hline & 7.577 & 1.0753 & 1.0960 & 1.1060 & 1.1236 & 1.1495 & 1.1638 & 1.1912 & 1.2186 & 1.2392 & 1.2646 \\
\hline & 8.177 & 1.0805 & 1.1030 & 1.1137 & 1.1329 & 1.1613 & 1.1770 & 1.2071 & 1.2368 & 1.2599 & 1.2886 \\
\hline & 8.737 & 1.0847 & 1.1085 & 1.1197 & 1.1403 & 1.1703 & 1.1869 & 1.2198 & 1.2520 & 1.2759 & 1.3072 \\
\hline & 9.263 & 1.0870 & 1.1118 & 1.1231 & 1.1445 & 1.1761 & 1.1935 & 1.2273 & 1.2611 & 1.2871 & 1.3191 \\
\hline & 9.760 & 1.0885 & 1.1137 & 1.1254 & 1.1471 & 1.1788 & 1.1966 & 1.2312 & 1.2658 & 1.2922 & 1.3261 \\
\hline & 10.233 & 1.0888 & 1.1142 & 1.1256 & 1.1475 & 1.1793 & 1.1969 & 1.2315 & 1.2657 & 1.2899 & 1.3141 \\
\hline & 10.685 & 1.0826 & 1.1048 & 1.1148 & 1.1353 & 1.1652 & 1.1810 & 1.2100 & 1.2343 & 1.2524 & 1.2722 \\
\hline & 11.119 & 1.0588 & 1.0758 & 1.0848 & 1.1015 & 1.1265 & 1.1396 & 1.1650 & 1.1935 & 1.2181 & 1.2478 \\
\hline & & \multicolumn{10}{|c|}{ Fan Total Temperature Ratio } \\
\hline & 6.204 & 1.0162 & 1.0206 & 1.0227 & 1.0264 & 1.0316 & 1.0345 & 1.0395 & 1.0443 & 1.0474 & 1.0519 \\
\hline & 6.924 & 1.0187 & 1.0237 & 1.0261 & 1.0303 & 1.0363 & 1.0397 & 1.0458 & 1.0519 & 1.0562 & 1.0617 \\
\hline & 7.577 & 1.0210 & 1.0266 & 1.0293 & 1.0341 & 1.0409 & 1.0447 & 1.0517 & 1.0586 & 1.0637 & 1.0701 \\
\hline & 8.177 & 1.0226 & 1.0287 & 1.0316 & 1.0369 & 1.0442 & 1.0483 & 1.0560 & 1.0637 & 1.0690 & 1.0762 \\
\hline & 8.737 & 1.0237 & 1.0303 & 1.0333 & 1.0389 & 1.0468 & 1.0512 & 1.0595 & 1.0674 & 1.0734 & 1.0807 \\
\hline & 9.263 & 1.0246 & 1.0313 & 1.0345 & 1.0403 & 1.0485 & 1.0532 & 1.0618 & 1.0703 & 1.0762 & 1.0843 \\
\hline & 9.760 & 1.0252 & 1.0321 & 1.0353 & 1.0413 & 1.0496 & 1.0542 & 1.0631 & 1.0718 & 1.0786 & 1.0866 \\
\hline & 10.233 & 1.0268 & 1.0344 & 1.0379 & 1.0443 & 1.0534 & 1.0585 & 1.0677 & 1.0772 & 1.0850 & 1.0956 \\
\hline & 10.685 & 1.0316 & 1.0406 & 1.0448 & 1.0525 & 1.0636 & 1.0699 & 1.0812 & 1.0918 & 1.0982 & 1.1082 \\
\hline & 11.119 & 1.0310 & 1.0398 & 1.0444 & 1.0527 & 1.0653 & 1.0724 & 1.0861 & 1.1008 & 1.1114 & 1.1240 \\
\hline & & \multicolumn{10}{|c|}{ Fan Adiabatic Efficiency } \\
\hline & 6.204 & 0.9893 & 0.9870 & 0.9894 & 0.9780 & 0.9740 & 0.9701 & 0.9655 & 0.9613 & 0.9623 & 0.9560 \\
\hline & 6.924 & 1.0000 & 0.9987 & 0.9970 & 0.9910 & 0.9923 & 0.9885 & 0.9892 & 0.9865 & 0.9870 & 0.9829 \\
\hline & 7.577 & 0.9998 & 0.9980 & 0.9981 & 0.9940 & 0.9939 & 0.9908 & 0.9916 & 0.9913 & 0.9923 & 0.9904 \\
\hline & 8.177 & 0.9905 & 0.9887 & 0.9876 & 0.9838 & 0.9876 & 0.9859 & 0.9862 & 0.9823 & 0.9889 & 0.9864 \\
\hline & 8.737 & 0.9905 & 0.9861 & 0.9865 & 0.9839 & 0.9817 & 0.9799 & 0.9821 & 0.9833 & 0.9816 & 0.9852 \\
\hline & 9.263 & 0.9809 & 0.9813 & 0.9786 & 0.9754 & 0.9780 & 0.9754 & 0.9758 & 0.9754 & 0.9814 & 0.9772 \\
\hline & 9.760 & 0.9746 & 0.9733 & 0.9724 & 0.9695 & 0.9701 & 0.9703 & 0.9698 & 0.9699 & 0.9669 & 0.9701 \\
\hline & 10.233 & 0.9175 & 0.9131 & 0.9073 & 0.9047 & 0.9033 & 0.9008 & 0.9061 & 0.9022 & 0.8879 & 0.8487 \\
\hline & 10.685 & 0.7255 & 0.7114 & 0.7041 & 0.7040 & 0.7021 & 0.6966 & 0.6893 & 0.6756 & 0.6763 & 0.6577 \\
\hline & 11.119 & 0.5316 & 0.5298 & 0.5304 & 0.5314 & 0.5300 & 0.5254 & 0.5181 & 0.5146 & 0.5205 & 0.5268 \\
\hline
\end{tabular}


Table 5A. Force balance performance data taken with Hardwall Vanes (HV) installed during HV-SV comparison test

\begin{tabular}{|c|c|c|c|c|}
\hline $\begin{array}{c}\text { Percent } \\
\begin{array}{c}\text { Corrected } \\
\text { Fan } \\
\text { Speed }\end{array}\end{array}$ & $\begin{array}{c}\text { Corrected } \\
\text { Fan } \\
\text { Thrust, } \\
\text { Ibf }\end{array}$ & $\begin{array}{c}\text { Corrected } \\
\text { Fan } \\
\text { Torque, } \\
\text { ft-lbs }\end{array}$ & $\begin{array}{c}\text { Corrected } \\
\text { Stage } \\
\text { Thrust, } \\
\text { Ibf }\end{array}$ & $\begin{array}{c}\text { Corrected } \\
\text { Total } \\
\text { Thrust, } \\
\text { Ibf }\end{array}$ \\
\hline 54.99 & 254.98 & 180.06 & 80.54 & 335.52 \\
62.01 & 327.91 & 230.83 & 111.23 & 439.14 \\
65.08 & 361.16 & 255.08 & 129.43 & 490.59 \\
70.00 & 421.42 & 296.23 & 154.61 & 576.03 \\
76.58 & 510.54 & 359.14 & 203.41 & 713.95 \\
80.03 & 557.56 & 394.34 & 231.46 & 789.02 \\
86.00 & 651.60 & 458.37 & 278.28 & 929.88 \\
95.38 & 803.76 & 566.72 & 362.02 & 1165.78 \\
100.04 & 875.53 & 620.23 & 401.36 & 1276.89 \\
& & & & \\
\hline
\end{tabular}

Table 5B. Force balance performance data taken with Soft Vanes (SV) installed during HV-SV comparison test

\begin{tabular}{|c|c|c|c|c|}
\hline $\begin{array}{c}\text { Percent } \\
\begin{array}{c}\text { Corrected } \\
\text { Fan } \\
\text { Speed }\end{array}\end{array}$ & $\begin{array}{c}\text { Corrected } \\
\text { Fan } \\
\text { Thrust, } \\
\text { Ibf }\end{array}$ & $\begin{array}{c}\text { Corrected } \\
\text { Fan } \\
\text { Torque, } \\
\text { ft-Ibs }\end{array}$ & $\begin{array}{c}\text { Corrected } \\
\text { Stage } \\
\text { Thrust, } \\
\text { Ibf }\end{array}$ & $\begin{array}{c}\text { Corrected } \\
\text { Total } \\
\text { Thrust, } \\
\text { Ibf }\end{array}$ \\
\hline 54.99 & 255.49 & 181.61 & 79.35 & 334.84 \\
62.02 & 326.08 & 231.19 & 112.00 & 438.08 \\
65.07 & 357.46 & 255.14 & 125.17 & 482.63 \\
70.01 & 419.31 & 297.68 & 158.67 & 577.98 \\
76.63 & 511.65 & 362.01 & 200.48 & 712.13 \\
80.01 & 560.32 & 397.28 & 227.67 & 787.99 \\
86.02 & 649.78 & 461.97 & 276.35 & 926.13 \\
95.40 & 803.77 & 571.51 & 355.66 & 1159.43 \\
100.02 & 877.07 & 704.70 & 393.81 & 1270.88 \\
& & & & \\
\hline
\end{tabular}





\begin{tabular}{|c|c|c|c|c|c|}
\hline \multicolumn{5}{|c|}{ REPORT DOCUMENTATION PAGE } & $\begin{array}{l}\text { Form Approved } \\
\text { OMB No. 0704-0188 }\end{array}$ \\
\hline \multicolumn{6}{|c|}{ 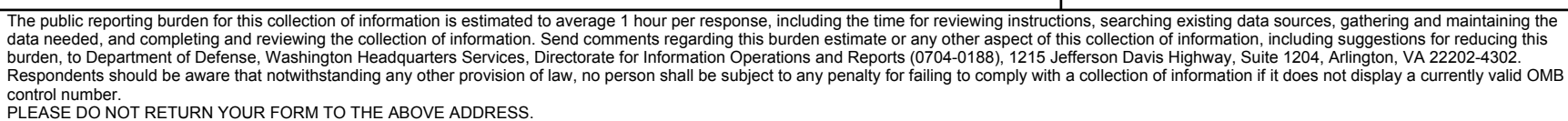 } \\
\hline \multicolumn{2}{|c|}{$\begin{array}{l}\text { 1. REPORT DATE (DD-MM-YYYY) } \\
01-11-2013\end{array}$} & \multicolumn{3}{|c|}{$\begin{array}{l}\text { 2. REPORT TYPE } \\
\text { Technical Memorandum }\end{array}$} & 3. DATES COVERED (From - To) \\
\hline \multirow{3}{*}{\multicolumn{5}{|c|}{$\begin{array}{l}\text { 4. TITLE AND SUBTITLE } \\
\text { Effect of Two Advanced Noise Reduction Technologies on the Aerodynamic Performance o } \\
\text { an Ultra High Bypass Ratio Fan }\end{array}$}} & 5a. CONTRACT NUMBER \\
\hline & & & & & 5b. GRANT NUMBER \\
\hline & & & & & 5c. PROGRAM ELEMENT NUMBER \\
\hline \multirow{3}{*}{\multicolumn{5}{|c|}{$\begin{array}{l}\text { 6. AUTHOR(S) } \\
\text { Hughes, Christopher, E.; Gazzaniga, John, A. }\end{array}$}} & 5d. PROJECT NUMBER \\
\hline & & & & & 5e. TASK NUMBER \\
\hline & & & & & $\begin{array}{l}\text { 5f. WORK UNIT NUMBER } \\
\text { WBS 561581.02.08.03.18.04 }\end{array}$ \\
\hline \multicolumn{5}{|c|}{$\begin{array}{l}\text { 7. PERFORMING ORGANIZATION NAME(S) AND ADDRESS(ES) } \\
\text { National Aeronautics and Space Administration } \\
\text { John H. Glenn Research Center at Lewis Field } \\
\text { Cleveland, Ohio 44135-3191 }\end{array}$} & $\begin{array}{l}\text { 8. PERFORMING ORGANIZATION } \\
\text { REPORT NUMBER } \\
\text { E-17121 }\end{array}$ \\
\hline \multirow{2}{*}{\multicolumn{5}{|c|}{$\begin{array}{l}\text { 9. SPONSORING/MONITORING AGENCY NAME(S) AND ADDRESS(ES) } \\
\text { National Aeronautics and Space Administration } \\
\text { Washington, DC 20546-0001 }\end{array}$}} & $\begin{array}{l}\text { 10. SPONSORING/MONITOR'S } \\
\text { ACRONYM(S) } \\
\text { NASA }\end{array}$ \\
\hline & & & & & $\begin{array}{l}\text { 11. SPONSORING/MONITORING } \\
\text { REPORT NUMBER } \\
\text { NASA/TM-2013-216073 }\end{array}$ \\
\hline \multicolumn{6}{|c|}{$\begin{array}{l}\text { 12. DISTRIBUTION/AVAILABILITY STATEMENT } \\
\text { Unclassified-Unlimited } \\
\text { Subject Category: } 71 \\
\text { Available electronically at http://www.sti.nasa.gov } \\
\text { This publication is available from the NASA Center for AeroSpace Information, 443-757-5802 }\end{array}$} \\
\hline \multicolumn{6}{|c|}{$\begin{array}{l}\text { 13. SUPPLEMENTARY NOTES } \\
\text { Portions of this material were presented at the 15th AIAA/CEAS Aeroacoustics Conference (30th AIAA Aeroacoustics Conference) } \\
\text { cosponsored by AIAA and CEAS, Miami, Florida, May 11-13, } 2009 .\end{array}$} \\
\hline \multicolumn{6}{|c|}{$\begin{array}{l}\text { 14. ABSTRACT } \\
\text { A wind tunnel experiment was conducted in the NASA Glenn Research Center anechoic 9- by 15-Foot Low-Speed Wind Tunnel to } \\
\text { investigate two new advanced noise reduction technologies in support of the NASA Fundamental Aeronautics Program Subsonic Fixed } \\
\text { Wing Project. The goal of the experiment was to demonstrate the noise reduction potential and effect on fan model performance of the two } \\
\text { noise reduction technologies in a scale model Ultra-High Bypass turbofan at simulated takeoff and approach aircraft flight speeds. The two } \\
\text { novel noise reduction technologies are called Over-the-Rotor acoustic treatment and Soft Vanes. Both technologies were aimed at modifying } \\
\text { the local noise source mechanisms of the fan tip vortex/fan case interaction and the rotor wake-stator interaction. For the Over-the-Rotor } \\
\text { acoustic treatment, two noise reduction configurations were investigated. The results showed that the two noise reduction technologies, } \\
\text { Over-the-Rotor and Soft Vanes, were able to reduce the noise level of the fan model, but the Over-the-Rotor configurations had a significant } \\
\text { negative impact on the fan aerodynamic performance; the loss in fan aerodynamic efficiency was between } 2.75 \text { to } 8.75 \text { percent, depending } \\
\text { on configuration, compared to the conventional solid baseline fan case rubstrip also tested. Performance results with the Soft Vanes showed } \\
\text { that there was no measurable change in the corrected fan thrust and a } 1.8 \text { percent loss in corrected stator vane thrust, which resulted in a total } \\
\text { net thrust loss of approximately } 0.5 \text { percent compared with the baseline reference stator vane set. }\end{array}$} \\
\hline \multicolumn{6}{|c|}{$\begin{array}{l}\text { 15. SUBJECT TERMS } \\
\text { Noise reduction; Vanes; Stators; High bypass; Turbofan; Wind tunnel; Scale model; Acoustics; Acoustic properties; Noise treatment; } \\
\text { Rotor; Noise (sound); Fan blades; Thrust; Aerodynamic characteristics; Fan adiabatic efficiency }\end{array}$} \\
\hline \multicolumn{3}{|c|}{ 16. SECURITY CLASSIFICATION OF: } & $\begin{array}{l}\text { 17. LIMITATION OF } \\
\text { ABSTRACT }\end{array}$ & $\begin{array}{l}\text { 18. NUMBER } \\
\text { OF }\end{array}$ & $\begin{array}{l}\text { 19a. NAME OF RESPONSIBLE PERSON } \\
\text { STI Help Desk (email:help@sti.nasa.gov) }\end{array}$ \\
\hline $\begin{array}{l}\text { a. REPORT } \\
\text { U }\end{array}$ & $\begin{array}{l}\text { b. ABSTRACT } \\
\text { U }\end{array}$ & $\begin{array}{l}\text { c. THIS } \\
\text { PAGE } \\
\text { U }\end{array}$ & UU & $\begin{array}{c}\text { PAGES } \\
30\end{array}$ & $\begin{array}{l}\text { 19b. TELEPHONE NUMBER (include area code) } \\
443-757-5802\end{array}$ \\
\hline
\end{tabular}



